Política y Sociedad

ISSN: $\quad 1130-8001$

ISSN-e: $1988-3129$

\title{
La "geometría variable": los gobiernos minoritarios de España en perspectiva espacial
}

\author{
Antonio Garrido ${ }^{1}$, María Antonia Martínez ${ }^{2}$ y Alberto Mora ${ }^{3}$
}

Recibido: 02-06-2019/ Aceptado: 28-11-2019

Resumen. Este artículo desarrolla, en el caso de España, el análisis de un tipo específico de gobiernos minoritarios, los de carácter sustantivo, desde una perspectiva espacial, con la pretensión de estudiar, el origen, viabilidad y formación de este tipo de gabinetes, así como las condiciones políticas necesarias para su estabilidad y efectividad. Asimismo, estudia los distintos subtipos de gobiernos minoritarios sustantivos, la variante más interesante de los gabinetes minoritarios, desarrollando la distinción entre gobiernos minoritarios de "geometría variable" y de "geometría estable". Esta conceptualización permite mostrar que los partidos centrales son más capaces de constituir y estabilizar gobiernos minoritarios, tanto formales como sustantivos y, especialmente, dar viabilidad a los gobiernos de "geometría variable". Los casos de los gobiernos minoritarios sustantivos españoles, desde 2004 a 2019, son analizados desde esta perspectiva, con especial atención a los gabinetes de José Luis Rodríguez Zapatero y Mariano Rajoy. El estudio, además, explora las condiciones políticas para el desarrollo de gobiernos minoritarios de "geometría variable" y algunos de sus elementos característicos, como el desarrollo de las "estrategias de empaquetado" o los cambios dinámicos en las alianzas y en los partidos de apoyo de este tipo de gabinetes.

Palabras clave: gobierno minoritario; agenda legislativa; geometría variable; España.

\section{[en] «Variable Geometry»: Minority Governments of Spain in Spatial Perspective}

\begin{abstract}
This article develops, in the case of Spain, the analysis of a specific type of minority government, the substantive minority government, from a spatial perspective, with the aim of studying the origin, viability and formation of this type of cabinet, as well as the political conditions necessary for their stability and effectiveness. Likewise, it studies the different subtypes of substantive minority government, including the most interesting variant, the minority cabinet, developing the distinction between "variable geometry" and "stable geometry" minority governments. This conceptualization allows us to show that the central parties are better able to constitute and stabilize minority governments, both formal and substantive, and, especially, to make "variable geometry governments viable. The cases of Spanish substantive minority governments, from 2004 to 2019, are analyzed from this perspective, with special attention to the cabinets of José Luis Rodríguez Zapatero and Mariano Rajoy. The study also explores the political conditions for the
\end{abstract}

\footnotetext{
Universidad de Murcia (España).

E-mail: agarrido@um.es

2 Universidad de Murcia (España).

E-mail: antoniam@um.es

3 Universidad de Murcia (España)

E-mail: alberto.mora@um.es
} 
development of "variable geometry" minority governments and some of their characteristic elements, such as the development of "packaging strategies" or the dynamic changes in alliances and support parties of this type of cabinet.

Keywords: minority government; legislative agenda; variable geometry; Spain.

Cómo citar: Garrido, A., M.A. Martínez y A. Mora (2020): "La "geometría variable": los gobiernos minoritarios de España en perspectiva espacial”, Politica y Sociedad, 57(1), pp. 45-75.

Sumario. 1. Introducción. 2. Las explicaciones teóricas de los gobiernos minoritarios y de la "geometría variable". 3. Los partidos como buscadores de cargos: viabilidad y estabilidad de los gobiernos minoritarios sustantivos. 4. Políticas: la efectividad de los gobiernos minoritarios sustantivos. 5. Conclusión. 6. Bibliografía

\section{Introducción ${ }^{4}$}

El gran número de gobiernos minoritarios en España es llamativo, pero no es una situación infrecuente en otros sistemas parlamentarios, donde constitucionalmente se requiere el apoyo de una mayoría de la cámara para poder formar Gobierno. Así, en una perspectiva comparada, un tercio de todos los gabinetes formados en las democracias parlamentarias han sido minoritarios, una realidad que confirman todos los estudios realizados: 35\% (Strom, 1990: 58); 33\% (Field, 2016: 9), etc. Sin embargo, la incidencia de los gobiernos minoritarios es muy superior en España a la media comparada: más del 64\% de los Gobiernos formados en España han sido minoritarios, y apenas el 35,7\% han sido Gobiernos mayoritarios. Incluso, si como sugieren algunos especialistas, como Lijphart (2012: 88), los "blocking cabinets", en los que el Gobierno tiene el apoyo de la mitad de los diputados del Congreso, como en el caso del Gobierno González III, puede ser atribuido indistintamente a la categoría de Gobiernos mayoritarios o minoritarios, el porcentaje de Gobiernos minoritarios en España sería casi del 68\%, es decir, que dos de cada tres Gobiernos españoles han sido minoritarios unipartidistas (Reniu, 2002 y 2011). Y, desde 2015 hasta 2019, pese al cambio acaecido en el sistema de partidos y su creciente fragmentación, todos los gobiernos han sido minoritarios.

La importancia de los gobiernos minoritarios en la política española es mayor aún si sólo se consideran las situaciones de minoría. A nivel comparado, entre 1945 y 2010, en contextos donde ningún partido ha obtenido una mayoría de los escaños, el $40 \%$ de los gobiernos formados fueron minoritarios (véase tabla 2). En España, en dichas situaciones, siempre se han constituido Gobiernos minoritarios, un porcentaje sólo igualado por Bulgaria (100\%) y más elevado que en los casos de países con frecuentes gobiernos minoritarios como Dinamarca (89\%), Noruega (79\%), Suecia (78\%), Rumania (73\%), etc. (Field, 2016: 8-10).

En España, el Gobierno no ha dependido, formalmente, de coaliciones de partidos y ha retenido el apoyo mayoritario de la legislatura casi el $43 \%$ del tiempo -de acuerdo a la ambigua consideración del "blocking cabinet" González III, que ha sido considerado en parte mayoritario y en parte minoritario (Tabla 2)-. El restante 57\% del tiempo (los Gobiernos han sido monocolores y unipartidistas, pero de carácter

El periodo de análisis abarca hasta las elecciones del 28 de abril de 2019. No se incluye el actual Gobierno en funciones. Los autores desean agradecer la ayuda a esta investigación de José Luis Molina Martos y Claudia Mayordomo Zapata. 
minoritario: UCD, el partido con mayor representación en la cámara, mantuvo el apoyo constante de una mayoría relativa cercana al $48 \%$ de los escaños, participando en pactos y compromisos ocasionales con otras fuerzas parlamentarias como los conservadores de AP y los nacionalistas catalanes (entre 1977 y 1982), y de nuevo hubo gobiernos minoritarios, con el apoyo de $\mathrm{CiU}, \mathrm{PNV}$ y otras formaciones nacionalistas, del PSOE entre 1993/1996 y 2004/2011 y, de nuevo, desde 2018 y del Partido Popular entre 1996/2000 y 2016/2018. Sólo entre 1982 y 1989/1993 el Partido Socialista y desde 2000/2004 y, de nuevo, entre 2011/2015 el Partido Popular han disfrutado de una mayoría absoluta de los votos en el Congreso de los Diputados, algo que no ocurre a menudo en los sistemas parlamentarios, y que ha sido debido a las primas en escaños que les venido otorgando el sistema electoral a los partidos más votados.

Pese a su extensión en el caso español y en otras democracias parlamentarias, el funcionamiento efectivo y las condiciones político-institucionales que permiten constituirse a los gobiernos minoritarios y mantenerse estables han presentado, hasta ahora, un puzzle teórico y político para los estudiosos de las coaliciones. Dos problemas dificultan el tratamiento de esta clase de gobiernos. Por un lado, una explicación conjunta del origen y de la supervivencia de estos gobiernos minoritarios resulta compleja de articular, lo que hace más operativo abordar por separado ambas cuestiones para ser más preciso en la identificación de los factores relevantes en cada uno de estos procesos. Asimismo, también se suelen estudiar, de manera conjunta, todos los gobiernos minoritarios, lo que impide comprender bien las singularidades que presentan los distintos subtipos de los mismos, especialmente, los gobiernos minoritarios formales y los gobiernos minoritarios sustantivos que, en cada una de esas dos dimensiones apuntadas (formación y estabilidad), presentan diferencias notables.

En las restantes secciones de este trabajo, abordaremos esta diferenciación entre gobiernos minoritarios formales y sustantivos, dado que en España, al igual que en Suecia y, recientemente, en Noruega, se ha experimentado con ambos modelos, en tanto que en otros países han tendido a prevalecer o bien los gobiernos minoritarios formales (como en Nueva Zelanda, desde 1996) o los sustantivos (como en Dinamarca), dificultando la comparación si se desea mantener constante el resto de variables (Román y Ferri, 2003: 21). ${ }^{5}$ Esta distinción, en su sentido original, aludía a gobiernos que sobrepasan o no, con apoyos externos, la barrera de la mayoría absoluta de escaños parlamentarios (Strom, 1990, 62). El segundo elemento de la distinción hacía mención a la constancia y regularidad o irregularidad de las coaliciones legislativas. Sin embargo, como ha señalado Bonnie Field, el caso español muestra la ambigüedad de estos subtipos, ya que algunos gobiernos minoritarios se han basado en "pactos de investidura" que no han sido, a posteriori, "pactos de legislatura", por lo que la diferenciación entre gobiernos minoritarios formales y sustantivos ha de basarse en la regularidad empírica de las coaliciones legislativas (la Tabla 3 muestra el apoyo inicial de cada gabinete); asimismo, como apunta Field (2016: 93), "los

En algunos países donde son frecuentes los gobiernos minoritarios, se ha desarrollado una tendencia creciente hacia los gobiernos minoritarios formales (Nueva Zelanda, Suecia y, recientemente, en Noruega), mientras que, antes de los años noventa, casi todos los gobiernos minoritarios en estos casos fueron sustantivos. En cambio, en España se ha desarrollado la tendencia contraria y, desde 2004, los gobiernos minoritarios han sido sustantivos en tanto que los gobiernos minoritarios de los años noventa habían sido formales. Los gobiernos minoritarios formales son escasos y sólo Italia, Israel, Dinamarca o Finlandia, antes de los años noventa, presentaban ejemplos de ellos (Strom, 1990: 94- 96). 
acuerdos con un partido de apoyo pueden permitir diversos grados de oposición (sin poner al gobierno en riesgo), y alianzas repetidas, con el mismo partido o grupo de partidos, también son posibles sin un acuerdo de apoyo formal." 6

Un modo de eludir los problemas de esta tipología de gobiernos minoritarios, que permite evitar algunas de estas dificultades, es considerar que los gobiernos minoritarios formales implican el mantenimiento de una "geometría estable" de apoyos parlamentarios, en tanto que los gobiernos minoritarios sustantivos se definen, más bien, por desarrollar una geometría "estable" o "variable", irregular y cambiante en sus grupos o partidos de apoyo. En este sentido, los gobiernos minoritarios formales tienden a constituir gobiernos de "geometría estable" y están basados en acuerdos con uno o varios partidos de apoyo, que permiten al gobierno disponer de un respaldo parlamentario constante y alcanzar el umbral de la mayoría absoluta, sin tener que ofrecer cargos ministeriales a estos grupos a cambio. Los gobiernos minoritarios sustantivos, en cambio, pueden constituir gobiernos de "geometría estable", con alianzas puntuales con un determinado grupo de partidos de apoyo, y, más frecuentemente, de "geometría variable", cambiando de alianzas, según las medidas políticas que intentan aprobar, y formando coaliciones ad hoc (Field, 2016: 97).

Sin embargo, el propio concepto de "geometría variable" no ha sido apenas utilizada en el estudio de los gobiernos minoritarios y la formación de coaliciones legislativas en España, donde su uso es frecuente, pero resulta un concepto de uso más político y periodístico que una categoría analítica plenamente incorporada al acervo de los estudios sobre gobiernos y coaliciones, por lo que intentaremos desarrollar una aproximación más rigurosa sobre el mismo.

En este trabajo desarrollamos la distinción entre gobiernos minoritarios formales, que son siempre de "geometría estable", y gobiernos minoritarios sustantivos, que pueden ser tanto de "geometría estable", como de "geometría variable", así como sus implicaciones para el proceso político y legislativo (Tabla 1).

Tabla 1. Subtipos de gobiernos minoritarios en España, 1977-2019

\begin{tabular}{|l|c|l|}
\hline & Gobiernos minoritarios formales & Gobiernos minoritarios sustantivos \\
\hline Geometría estable & González IV & $\begin{array}{l}\text { Rajoy II } \\
\text { Sánchez I }\end{array}$ \\
\hline Geometría variable & - & $\begin{array}{l}\text { Suárez I y II } \\
\text { Zapatero I y II }\end{array}$ \\
\hline
\end{tabular}

Fuente: elaboración propia.

Utilizando algunos modelos formales, describiremos los problemas de los gobiernos minoritarios sustantivos, que no están posicionados en el centro del espacio político, para ser estables y también para poder desarrollar su agenda

Los diversos grados de oposición que pueden desarrollar los partidos de apoyo a un gobierno minoritario han sido objeto de recientes análisis, tanto desde el punto de vista de sus niveles de colaboración como de sus consecuencias en políticas concretas o en el control del déficit (Christiansen y Damgaard, 2008; Falcó-Gimeno y Jurado, 2011). 
legislativa; el simple contraste entre los recientes gabinetes Zapatero I y II y Rajoy II es elocuente al respecto.

Tabla 2. Tipos de gobierno mayoritarios y minoritarios (sustantivos y formales) en España, 1977-2019

\begin{tabular}{|c|c|c|c|c|c|c|c|c|}
\hline $\begin{array}{l}\text { Presidente } \\
\text { del Gobierno }\end{array}$ & $\begin{array}{l}\text { Tipo de } \\
\text { Gobierno }\end{array}$ & Carácter & Partido & Nombramiento & Cese & $\begin{array}{l}\text { Duración } \\
\text { (en días) }\end{array}$ & $\begin{array}{l}\text { Duración } \\
\text { (en años) }\end{array}$ & $\begin{array}{l}\text { Formación } \\
\text { (días) }\end{array}$ \\
\hline Suárez & Minoritario & Sustantivo & UCD & - & - & - & - & - \\
\hline Suárez II & Minoritario & Sustantivo & UCD & $30 / 03 / 79$ & $29 / 01 / 81$ & 671 & 1.84 & 29 \\
\hline Calvo Sotelo & Minoritario & Sustantivo & UCD & $25 / 02 / 81$ & $29 / 10 / 82$ & 611 & 1.67 & 27 \\
\hline González I & Mayoritario & - & PSOE & $01 / 12 / 82$ & $23 / 06 / 86$ & 1300 & 3.56 & 33 \\
\hline González II & Mayoritario & - & PSOE & $23 / 07 / 86$ & $30 / 10 / 89$ & 1195 & 3.27 & 30 \\
\hline González III & $\begin{array}{l}\text { Mayoritario/ } \\
\text { Minoritario }\end{array}$ & - & PSOE & $05 / 12 / 89$ & $07 / 06 / 93$ & 1280 & 3.51 & 36 \\
\hline González IV & Minoritario & Formal & PSOE & 09/07/93 & $04 / 03 / 86$ & 969 & 2.65 & 32 \\
\hline Aznar I & Minoritario & Formal & PP & $04 / 05 / 96$ & $13 / 03 / 00$ & 1409 & 3.86 & 61 \\
\hline Aznar II & Mayoritario & - & PP & $26 / 04 / 00$ & $15 / 03 / 04$ & 1419 & 3.89 & 44 \\
\hline Zapatero I & Minoritario & Sustantivo & PSOE & $16 / 04 / 04$ & $10 / 03 / 08$ & 1424 & 3.90 & 32 \\
\hline Zapatero II & Minoritario & Sustantivo & PSOE & $11 / 04 / 08$ & $21 / 10 / 11$ & 1319 & 3.61 & 32 \\
\hline Rajoy I & Mayoritario & - & PP & $20 / 12 / 11$ & $21 / 12 / 15$ & 1462 & 4.00 & 30 \\
\hline Rajoy II & Minoritario & Sustantivo & PP & $04 / 11 / 16$ & $01 / 06 / 18$ & 573 & 1.57 & 129 \\
\hline Sánchez I & Minoritario & Sustantivo & PSOE & $01 / 06 / 18$ & $29 / 04 / 19$ & 333 & 0.91 & 0 \\
\hline \multicolumn{6}{|c|}{ Media (1979-2018) } & 1074 & 2.94 & 39.61 \\
\hline & \multicolumn{5}{|c|}{ Media Gobiernos Mayoritarios (1979-2018) } & 1331.2 & 3.65 & 34.60 \\
\hline & \multicolumn{5}{|c|}{ Media Gobiernos Minoritarios (1979-2018) } & 954.33 & 2.61 & 42.00 \\
\hline
\end{tabular}

Fuente: elaboración propia. 
Tabla 3. Gobiernos en España, 1977-2019

\begin{tabular}{|c|c|c|c|c|c|c|}
\hline Gobierno & $\begin{array}{l}\text { Fecha } \\
\text { voto }\end{array}$ & Resultado & $\begin{array}{l}\text { Votos } \\
\text { sí }\end{array}$ & $\begin{array}{c}\text { Votos } \\
\text { no }\end{array}$ & Abstención & Partidos de apoyo \\
\hline \multicolumn{7}{|c|}{ Votos de investidura } \\
\hline Suárez & - & - & - & - & - & - \\
\hline Suárez II & $30 / 03 / 79$ & $\begin{array}{l}\text { Formado, } \\
1^{\text {a }} \text { votación }\end{array}$ & 183 & 149 & 8 & $\begin{array}{l}\text { UCD (168), CD (8), PSA-PA (5), } \\
\text { PAR (1), UPN (1) }\end{array}$ \\
\hline $\begin{array}{l}\text { No formado } \\
\text { (Calvo Sotelo) }\end{array}$ & $20 / 02 / 81$ & $\begin{array}{l}\text { Rechazado, } 1^{\text {a }} \\
\text { votación }\end{array}$ & 169 & 158 & 17 & UCD (165), CD (3), UPN (1) \\
\hline $\begin{array}{l}\text { No formado } \\
\text { (Calvo Sotelo) }\end{array}$ & $23 / 02 / 81$ & Golpe de estado & - & - & - & - \\
\hline Calvo Sotelo & $25 / 02 / 81$ & $\begin{array}{l}\text { Formado, } \\
2^{\mathrm{a}} \text { votación }\end{array}$ & 186 & 158 & 0 & $\begin{array}{l}\text { UCD (165), CiU (9), CD (9), } \\
\text { PAR (1), UPN (1), Indep. (1) }\end{array}$ \\
\hline González I & $01 / 12 / 82$ & $\begin{array}{l}\text { Formado, } \\
1^{\text {a }} \text { votación }\end{array}$ & 207 & 116 & 22 & $\begin{array}{l}\text { PSOE (200), PCE (4), CDS (2), } \\
\text { EE (1) }\end{array}$ \\
\hline González II & $23 / 07 / 86$ & $\begin{array}{l}\text { Formado, } \\
1^{\text {a }} \text { votación }\end{array}$ & 184 & 141 & 6 & PSOE (184) \\
\hline González III & $05 / 12 / 89$ & $\begin{array}{l}\text { Formado, } \\
1^{\text {a }} \text { votación }\end{array}$ & 167 & 155 & 6 & PSOE (166), AIC (1) \\
\hline González IV & $09 / 07 / 93$ & $\begin{array}{l}\text { Formado, } \\
1^{\text {a }} \text { votación }\end{array}$ & 181 & 165 & 1 & PSOE (159), CiU (17), PNV (5) \\
\hline Aznar I & $04 / 05 / 96$ & $\begin{array}{l}\text { Formado, } \\
1^{\text {a }} \text { votación }\end{array}$ & 181 & 166 & 1 & $\begin{array}{l}\text { PP (156), CiU (16), PNV (5), } \\
\text { CC (4) }\end{array}$ \\
\hline Aznar II & $26 / 04 / 00$ & $\begin{array}{l}\text { Formado, } \\
1^{\text {a }} \text { votación }\end{array}$ & 202 & 148 & 19 & PP (183), CiU (15), CC (4) \\
\hline Zapatero I & $16 / 04 / 04$ & $\begin{array}{l}\text { Formado, } \\
1^{\text {a }} \text { votación }\end{array}$ & 183 & 148 & 0 & $\begin{array}{l}\text { PSOE (164), ERC (8), IU (5), } \\
\text { CC (3), BNG (2), ChA (1) }\end{array}$ \\
\hline $\begin{array}{l}\text { No formado } \\
\text { (Zapatero) }\end{array}$ & $09 / 04 / 08$ & $\begin{array}{l}\text { Rechazado, } 1^{\mathrm{a}} \\
\text { votación }\end{array}$ & 168 & 158 & 23 & PSOE (168) \\
\hline Zapatero II & $11 / 04 / 08$ & $\begin{array}{l}\text { Formado, } \\
2^{\mathrm{a}} \text { votación }\end{array}$ & 169 & 158 & 23 & PSOE (169) \\
\hline Rajoy I & $20 / 12 / 12$ & $\begin{array}{l}\text { Formado, } \\
1^{\text {a }} \text { votación }\end{array}$ & 187 & 149 & 14 & PP (185), UPN (1), FA (1) \\
\hline $\begin{array}{l}\text { No formado } \\
\text { (Sánchez) }\end{array}$ & $02 / 03 / 16$ & $\begin{array}{l}\text { Rechazado, } 1^{\text {a }} \\
\text { votación }\end{array}$ & 130 & 219 & 1 & PSOE (89), C's (40), NC (1) \\
\hline $\begin{array}{l}\text { No formado } \\
\text { (Sánchez) }\end{array}$ & $04 / 03 / 16$ & $\begin{array}{l}\text { Rechazado, } 2^{\mathrm{a}} \\
\text { votación }\end{array}$ & 131 & 219 & 0 & $\begin{array}{l}\text { PSOE (89), C's (40), CC (1), } \\
\text { NC (1) }\end{array}$ \\
\hline $\begin{array}{l}\text { No formado } \\
\text { (Rajoy) }\end{array}$ & $31 / 08 / 16$ & $\begin{array}{l}\text { Rechazado, } 1^{\text {a }} \\
\text { votación }\end{array}$ & 170 & 180 & 0 & $\begin{array}{l}\text { PP (134), C's (32), CC (1), } \\
\text { FAC (1), UPN (2) }\end{array}$ \\
\hline $\begin{array}{l}\text { No formado } \\
\text { (Rajoy) }\end{array}$ & $02 / 09 / 16$ & $\begin{array}{l}\text { Rechazado, } 2^{\mathrm{a}} \\
\text { votación }\end{array}$ & 170 & 180 & 0 & $\begin{array}{l}\text { PP (134), C's (32), CC (1), } \\
\text { FAC (1), UPN (2) }\end{array}$ \\
\hline
\end{tabular}




\begin{tabular}{|c|c|c|c|c|c|c|}
\hline Gobierno & $\begin{array}{l}\text { Fecha } \\
\text { voto }\end{array}$ & Resultado & $\begin{array}{l}\text { Votos } \\
\text { sí }\end{array}$ & $\begin{array}{c}\text { Votos } \\
\text { no }\end{array}$ & Abstención & Partidos de apoyo \\
\hline $\begin{array}{l}\text { No formado } \\
\text { (Rajoy) }\end{array}$ & $27 / 10 / 16$ & $\begin{array}{l}\text { Rechazado, } 1^{\mathrm{a}} \\
\text { votación }\end{array}$ & 170 & 180 & 0 & $\begin{array}{l}\text { PP (134), C's (32), CC (1), } \\
\text { FAC (1), UPN (2) }\end{array}$ \\
\hline Rajoy II & $04 / 11 / 16$ & $\begin{array}{l}\text { Formado, } \\
2^{\mathrm{a}} \text { votación }\end{array}$ & 170 & 111 & 68 & $\begin{array}{l}\text { PP (134), C's (32), CC (1), } \\
\text { FAC (1), UPN (2) }\end{array}$ \\
\hline \multicolumn{7}{|c|}{ Cuestiones de confianza } \\
\hline Suárez II & $16 / 09 / 80$ & Aprobada & 180 & 164 & 2 & $\begin{array}{l}\text { UCD (165), CiU (8), PA (5), } \\
\text { Indep. (2) }\end{array}$ \\
\hline González III & $05 / 04 / 90$ & Aprobada & 176 & 130 & 37 & PSOE (175), AIC (1) \\
\hline \multicolumn{7}{|c|}{ Mociones de censura } \\
\hline Suárez II & $30 / 05 / 80$ & Rechazada & 152 & 166 & 21 & $\begin{array}{l}\text { PSOE (120), PCE (23), PA (5), } \\
\text { EE (1), ERC (1), UPC (1), Indep. (1) }\end{array}$ \\
\hline González II & $30 / 03 / 87$ & Rechazada & 67 & 194 & 71 & AP (66), UV (1) \\
\hline Rajoy II & $14 / 06 / 17$ & Rechazada & 82 & 170 & 97 & Podemos (71), ERC (9), EH (2) \\
\hline Sánchez & $01 / 06 / 18$ & $\begin{array}{l}\text { Cambio de } \\
\text { Gobierno }\end{array}$ & 180 & 169 & 1 & $\begin{array}{l}\text { PSOE (84), Podemos (71), ERC (9), } \\
\text { PDeCAT (8), PNV (5), EH (2), NC (1) }\end{array}$ \\
\hline
\end{tabular}

Fuente: elaboración propia.

En resumen, este artículo pretende, desde una perspectiva espacial, que no ha sido aplicada hasta ahora, analizar las variantes internas y, especialmente, los gobiernos minoritarios sustantivos, que constituyen el subtipo más numeroso, con el objetivo de entender sus condiciones de viabilidad, estabilidad y efectividad. Asimismo, pretendemos, desarrollar, conceptual y analíticamente, la distinción entre gobiernos minoritarios sustantivos de "geometría variable" y de "geometría estable".

En el primer apartado, se analizan las teorías que dan sustento al análisis y se formulan las hipótesis de la investigación. Los apartados siguientes abordan el proceso de formación y la gestión de estos gabinetes, centrando el análisis en la problemática específica de los gobiernos minoritarios sustantivos. La segunda sección está centrada en la fase de formación de los gobiernos minoritarios. El tercer epígrafe evalúa la efectividad de los gobiernos minoritarios para llevar adelante su agenda legislativa. El estudio se cierra con un breve apartado de conclusiones.

\section{Las explicaciones teóricas de los gobiernos minoritarios y de la "geometría variable"}

Las clásicas teorías formales, tenían como premisa principal la búsqueda de cargos o, residualmente, la búsqueda de políticas, y tendían a predecir determinados resultados en base a estos supuestos: coaliciones mínimas vencedoras, coaliciones de tamaño 
mínimo, coaliciones centradas en el número mínimo de partidos, coaliciones de distancia mínima o coaliciones mínimas conectadas, etc. (Lijphart, 2012: 80-85). Dada la complejidad de los fenómenos coalicionales, sin embargo, las teorías formales fueron desplazadas por otras explicaciones multidimensionales centradas en las distintas funciones que desarrollan los partidos, como buscadores de votos, cargos y políticas (vote-seeking, office-seeking y policy-seeking), de acuerdo a la clásica distinción de Strom.

El estudio de los gobiernos minoritarios ha permitido la articulación de explicaciones multidimensionales similares. Así, a partir de la identificación de los objetivos de los partidos se han desarrollado explicaciones alrededor de estos objetivos: búsqueda de cargos, votos, políticas, cohesión partidista y política multinivel (Petersen y De Ridder, Harmel y Janda, Bergman, etc.). Por otra parte, desde perspectivas basadas en las distintas arenas en las que operan los partidos y en las que se producen los intercambios partidistas se han delimitado las condiciones de viabilidad y de estabilidad de los gobiernos minoritarios, analizando diferentes arenas (Maor, Mitchell, etc.): la intrapartidista, la interpartidista, la institucional y la electoral; legislativa, organizativa, electoral y de políticas, etc. (Bergman, 1995; Reniu, 2002).

En el presente trabajo, abarcaremos dos de los tradicionales objetivos de los partidos que forman gobiernos según han sido analizados por las teorías multidimensionales: las perspectivas "office seeking" (buscadores de cargos) y "policy seeking" (buscadores de políticas). De este modo intentamos desarrollar un análisis más parsimonioso, centrando el estudio sólo en estos dos objetivos, que son "intrínsecos" y predominantes, para las formaciones políticas que han llegado a constituir gobiernos, como UCD, PSOE y PP, como bien señalan los estudiosos que se inscriben dentro de las explicaciones multidimensionales (Reniu, 2002: 190); otros objetivos, como la búsqueda de votos o la cohesión interna partidaria son objetivos simplemente "instrumentales" para estos partidos formadores de gobiernos, aunque bien pueden ser "intrínsecos" para los partidos de apoyo, como sucede en el caso español con los partidos nacionalistas o regionalistas.

En consecuencia, abordaremos estos objetivos desde una perspectiva espacial. En relación con los gobiernos minoritarios, las aproximaciones espaciales han desarrollado dos interpretaciones: las teorías posicionales y las teorías de la proximidad ideológica. Las teorías posicionales sostienen que los gobiernos minoritarios son más viables y efectivos si están centralmente localizados en el espacio político. De este modo, pueden impedir que se formen otros gobiernos alternativos y también son más capaz de obtener apoyo para sus propuestas legislativas pactando a izquierda y derecha, en función del tipo de políticas y de la posición del status quo en cada caso. La ubicación central del Ejecutivo aumenta su poder de negociación y permite realizar transacciones a un lado y a otro del espectro político y en distintas dimensiones, cuando los cleavages del conflicto político son diversos; como sucede en España, debido la bidimensionalidad de las líneas de fractura que cruzan el eje izquierda/derecha con el eje centralismo/autonomismo de la política territorial multinivel (Colomer y Martínez, 1995; Heller, 2002; Hamann y Mershon, 2008; Stefuriuc, 2013; Field, 2014 y 2016: 141-206). Cuando el Gobierno no incluye al legislador medio, sus propuestas legislativas pueden ser revisadas o 
rechazadas y el resultado final se inclinará hacia la preferencia ideal del partido de la oposición que contiene al legislador medio.

Esta perspectiva permite generar dos posibles hipótesis a contrastar:

H1: La probabilidad de que un gobierno minoritario sustantivo vete a todos los demás posibles gabinetes alternativos es más alta si el Gobierno está situado en la posición central en el parlamento.

$\mathrm{H} 2$ : La probabilidad de que las propuestas legislativas de un gobierno minoritario sustantivo sea aprobada es más alta si el Gobierno ocupa una posición central en el parlamento.

En segundo lugar, las teorías de la distancia o proximidad ideológica de los partidos de la oposición al gabinete minoritario sostienen que la posición negociadora de este es más fuerte si los partidos opositores son más compatibles y/o están más próximos espacialmente (Klüver y Zubek, 2018). ${ }^{7}$ El mayor o menor grado de afinidad ideológica entre los denominados partidos de apoyo y los gabinetes minoritarios tiene un fuerte impacto sobre las estrategias de construcción de coaliciones legislativas del Ejecutivo. Las concesiones que deben realizar los gabinetes minoritarios a sus partidos de apoyo serán menores si aumenta la proximidad ideológica entre ellos y se incrementarán si los partidos de la oposición que dan cobertura a las políticas del Gobierno están muy alejados política y espacialmente de este. En este estudio, exploraremos la primera de estas interpretaciones y su potencial para explicar el caso español, dejando de lado esta segunda perspectiva para un posterior análisis.

\section{Los partidos como buscadores de cargos: viabilidad y estabilidad de los gobiernos minoritarios sustantivos}

En este apartado, centraremos la atención en la génesis y formación de los gobiernos minoritarios españoles, que parecen mejor explicados en términos de "office seeking", la perspectiva de los partidos como buscadores de cargos. ${ }^{8}$ Utilizando modelos formales ilustraremos las dificultades de los partidos que no están posicionados en el centro del espacio político para estabilizar este tipo de gabinetes, dada su vulnerabilidad estratégica, por lo que, en algunos casos, estos gobiernos son viables pero no estables (Rajoy II) y, en otros casos, son tanto viables como estables (Zapatero I y II).

\footnotetext{
En perspectiva comparada, los contextos de elevada polarización partidista parecen estar asociados a la proliferación de gobiernos minoritarios (Green-Pedersen, 2001; Klüver y Zubek, 2018). Los países que presentan sistemas de partidos muy polarizados tienen un elevado porcentaje de gobiernos minoritarios: España, Dinamarca, Suecia, Noruega, Polonia o la República Checa. En cambio, donde pese al multipartidismo, la polarización es media o baja, los gobiernos minoritarios son infrecuentes: Alemania, Holanda, Finlandia, Grecia, etc. Excepcionalmente, hay casos desviantes de gobiernos minoritarios con baja polarización (Rumania) o ausencia de gobiernos minoritarios con elevada polarización (Islandia o Bélgica). El caso español es un ejemplo de esta relación entre polarización y gobiernos minoritarios, con índices Dalton por encima de 4,0 en casi todos los casos de gabinetes minoritarios (González IV, Aznar I, Zapatero I y II, Rajoy II y Sánchez I), con la excepción de los gobiernos de Suárez.

8 No se debe olvidar la influencia de las reglas de decisión para la investidura y otras disposiciones constitucionales (Bergman, 1993 y 1995; Cheibub, Martin y Rasch, 2015). En España, las normas que regulan el voto de investidura y la censura, han tenido un cierto impacto sobre el tipo de gobierno (Ajenjo, 2015).
} 
El contraste entre viabilidad y estabilidad estratégica de los gobiernos minoritarios está relacionado, principalmente, con su posición de centralidad en el espacio político y su mayor o menor proximidad al umbral de la mayoría absoluta de los escaños (Garrido, 1995: 135-136). En primer término, hay que tener en cuenta, que un gobierno minoritario no necesita estar situado en una posición central en el espacio político para formarse, como muestran los gobiernos minoritarios del PP (Aznar I y Rajoy II). En 1996, el Partido Popular gobernó en minoría mediante un pacto de legislatura con CiU, PNV y CC, a pesar de su lejanía de la media de la distribución de preferencias ideológicas: el electorado en su conjunto le asignaba el 7,9 de la escala, aunque sus votantes tenían una percepción mucho más moderada y lo ubicaban en el 6,5, puntos lejanos del 4,7 en que se situaba el votante medio (cerca del 4,5 del PSOE). Lo mismo cabe afirmar en el proceso de formación de Gobierno en 2016, tanto en la XI como en la XII Legislatura: desde esta perspectiva, el "formateur" del Gobierno debería haber sido el PSOE con su líder Pedro Sánchez, formación percibida $(4,60)$ como mucho más próxima al votante medio $(4,67)$ y más próxima al partido que contenía al legislador medio en dicho parlamento, el PNV $(6,20)$, que el $\mathrm{PP}$, que, finalmente, formó Gobierno. De este modo, podríamos sugerir que un partido no central puede constituir un gobierno minoritario formal, como muestra el gabinete Aznar I, y hacer estable un gabinete parlamentario, pero experimentará notables dificultades para hacer viable y estabilizar un gobierno minoritario sustantivo, como sucedió en el caso de Rajoy II. Los partidos centrales pueden, por supuesto, constituir gobiernos minoritarios formales, como el gabinete socialista González IV, pero también gobiernos minoritarios sustantivos, como los gobiernos de Zapatero I y II; también en Suecia, sus equivalentes socialdemócratas han oscilado entre gobiernos minoritarios sustantivos, como en 1998 y en etapas anteriores, o más formales, basados en documentos públicos, como en 2002, que han permitido a algunos analistas acuñar el término de "contract parliamentarianism" o "parlamentarismo contractual" (Bale y Bergman, 2004).

Además de la posición central de los partidos encargados de formar gobierno, un segundo factor relevante es la proximidad de los gobiernos minoritarios españoles a la mayoría absoluta de escaños, a diferencia del resto de países donde son frecuentes este tipo de gabinetes, como Dinamarca, Suecia o Noruega, como refleja el Gráfico 1. Por eso, ha sido la reducción de escaños de los grandes partidos, PP y PSOE, en 2016, la que ha hecho más complejo gobernar en minoría que en legislaturas anteriores, en las que el primer partido tenía un porcentaje de escaños muy cercano y próximo a la mayoría absoluta. En este nuevo escenario, el otro factor, la centralidad del partido "formateur" ha cobrado más relevancia.

En cuanto a las condiciones de estabilidad, un gobierno minoritario constituido alrededor de un partido no central siempre es, potencialmente, susceptible de ser derrotado y removido por la cámara, como sucedió en junio de 2018 con el Gobierno Rajoy II. El elemento decisivo, no sólo para su viabilidad sino para su estabilidad, es tener una posición moderada en el espectro político y su capacidad de veto sobre el resto de gabinetes alternativos que pudieran ganar una base de apoyo en el parlamento, como el gabinete alternativo dirigido por Pedro Sánchez, del PSOE en el cambio de Gobierno en 2018. En consecuencia, este tipo de partidos no centrales, generalmente, se ven forzados a formar gobiernos minoritarios formales o de "geometría estable", si desean ser viables y estables, 
constituyendo, así, ejecutivos casi mayoritarios o próximos a una mayoría. En cambio, les resulta difícil mantener gobiernos minoritarios sustantivos y de "geometría variable", debido a su posición espacial no centrista.

Gráfico 1. Porcentaje de escaños de gobiernos en España, Dinamarca, Suecia y Noruega

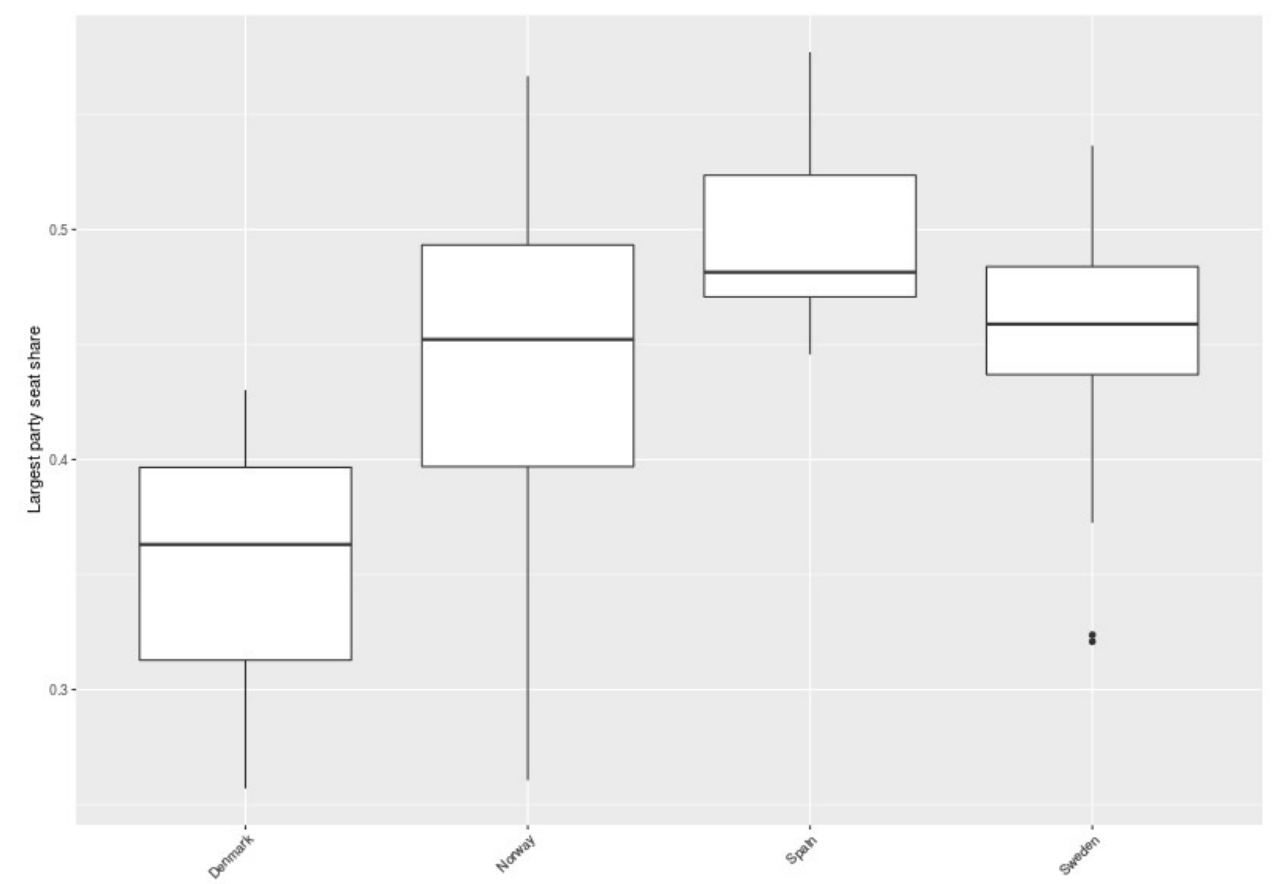

Fuente: Hellstöm, J; Bergman, T.; Bäck, H. (2018). Party Government in Europe Database.

Disponible en:

https:/erdda.org/party-government-in-Europe-database/

Así, desde el punto de vista de su viabilidad, un gobierno minoritario formal y de "geometría estable" puede estar basado en partidos centrales (González IV) o no centrales (Aznar I). En cambio, un gobierno minoritario sustantivo depende de su centralidad espacial y debe estar situado en una posición central (Zapatero I y II), si pretender mantener una cierta estabilidad. Así, la mayoría de los gabinetes minoritarios sustantivos españoles (Suárez I y II, Zapatero I y II) han sido gobiernos con una cierta proximidad de los mismos respecto al legislador medio.

Como ya señalaron Laver y Shepsle (1996: 191), "la evidencia empírica sugiere que las fuerzas centrípetas son extraordinariamente importantes para formar y derribar Gobiernos" en sistemas parlamentarios y con gran frecuencia los partidos moderados que ocupan posiciones centrales en la escala espacial suelen formar la base de los gabinetes y/o de las coaliciones que los apoyan. A este respecto, los estudios sobre modelos espaciales, aplicados a la teoría de las coaliciones, tienden a subrayar la gran influencia estratégica de los partidos centrales en estos escenarios parlamentarios. 
Si analizamos algunos gobiernos minoritarios españoles, según el modelo de Laver-Shepsle, conociendo las posiciones que ocupan espacialmente los diferentes actores políticos (a partir de la percepción ciudadana registrada por las encuestas del CIS), su fuerza respectiva en la asamblea (número de escaños controlados por cada partido), sus funciones de utilidad en relación con las alternativas que se les presentan, y las reglas de decisión relativas a los votos de investidura y censura, y estando formada la estructura de decisión de la cámara por el conjunto de las coaliciones vencedoras, se puede comprobar la importancia que los partidos centrales han tenido en el proceso de formación de gobiernos minoritarios (Montabes, Garrido y Martínez, 2019: 217-218). ${ }^{9}$

Simplificando, los puntos PSOE, PP, IU, PNV, CiU, etc. indican que todas las carteras del gabinete serán ocupadas por un único partido mientras que, por ejemplo, una fórmula PSOE-IU implica conceder puestos ministeriales a ambos grupos, y así hasta completar el resto de las combinaciones posibles entre los distintos partidos con representación parlamentaria. Las curvas de indiferencia de cada partido al pasar sobre cada una de estas fórmulas de gobierno de coalición muestran los puntos y las alternativas que cada grupo prefiere antes que cualquiera de dichas combinaciones y los pétalos formados por la intersección de las curvas de indiferencia constituyen las áreas (winset) que contienen los puntos que alguna mayoría (coalición mínima vencedora) considera preferibles al "status quo".

El Gráfico 2 muestra que varias coaliciones alternativas pudieron formarse en 2008, como la constituida por PSOE e IU, por ejemplo. En 2004 y 2008, esta coalición era capaz de contar con un apoyo de mayoría en la cámara, con todas las dificultades imaginables. Sin embargo, su misma vulnerabilidad estratégica, ya que varios gobiernos y distintas coaliciones alternativas se encuentran en el winset de dicha coalición, como muestra el Gráfico 2, permitieron la constitución de un gobierno minoritario del PSOE en solitario.

Un gabinete minoritario sustantivo del PSOE también constituía un Ejecutivo en equilibrio, en el cual este partido era capaz de implementar una política muy cercana a su punto ideal, a pesar de no disponer de una mayoría en la cámara. Con esta ubicación, el PSOE no tenía especiales dificultades para formar coaliciones más o menos permanentes o puntuales con otros grupos afines a ambos lados del espectro: con IU, los regionalistas o nacionalistas de CiU o del PNV e incluso con el PP en una suerte de Grosse Koalition. Geométricamente, cualquier coalición del PSOE (por ejemplo, PSOE con IU o PSOE con CiU) constituía un Ejecutivo invulnerable dentro de la asamblea y un equilibrio en el juego de formación del gabinete. Sin embargo, un Gobierno minoritario sustantivo del PSOE también era un gabinete en equilibrio, como se observa en el gráfico, al constituir el PSOE un partido "fuerte" (Laver y Shepsle, 1996: 69-78), "central" (Van Roozendaal, 1993) o "nuclear" (Schofield, 1993: 8), un partido que, según la clásica conceptualización de Val Lorwin, tiene capacidad para hacer coaliciones a derecha e izquierda -Allgemein-koalitionsfahigkeit-). Es esta localización central la que le permitió

La metodología utilizada en este apartado para explicar la formación de gobiernos minoritarios tiene su origen en las clásicas aproximaciones espaciales de Black y Downs, que ya subrayaban la importancia de las tendencias centristas en la competencia política. El análisis, en todo caso, se inspira en el enfoque de Baron (1991) y, especialmente, en un modelo departamentalista de formación de gobiernos en equilibrio, cuyas premisas metodológicas y una prueba formal del mismo se presentan en Laver y Shepsle, 1996: 61-89. Modelos formales y espaciales, con una metodología similar, pueden encontrarse en Austen-Smith y Banks (1990), Schofield (1993), etc. 
reforzar su poder de negociación, gracias a una mayor proximidad al resto de aliados potenciales que sus posibles competidores.

Un partido "fuerte", según Laver-Shepsle, es aquel que, ocupando una posición espacial central, difícilmente puede ser excluido del gobierno puesto que ningún otro gabinete es preferido por una mayoría (el caso de la coalición entre PSOE e IU) o bien dicho partido puede excluir o vetar los gabinetes alternativos preferidos por una mayoría (el caso de un gobierno en minoría del PSOE). Pues bien, el hecho de que el PSOE, que, lógicamente, prefiere implementar su punto ideal antes que cualquier otra política, pueda usar su poder de veto para impedir la formación de los gabinetes alternativos que se encuentran en su winset (en ambas coaliciones PSOE-IU y PSOE-CiU debe necesariamente participar el PSOE) significa que dicho gabinete constituye un equilibrio para esta asamblea y que el PSOE es miembro de cualquier gabinete en equilibrio que pueda formarse

Un partido "fuerte", "central" o "nuclear", en los términos de Laver-Sheplse, Schofield y otros, puede excluir y vetar los gabinetes alternativos. Por ello, se trata de un actor focal en el proceso de formación de Gobiernos, que suele encontrarse, con frecuencia, en espacios políticos de pocas dimensiones -cleavages-, en sistemas multipartidistas con una baja fragmentación y en estructuraciones partidistas que tienen un actor dominante, o una desigual distribución de fuerzas.

Estos partidos se caracterizan por ser formaciones de gran peso parlamentario, situadas cerca de la posición media en una o más de las dimensiones del sistema político; una descripción que presenta una gran similitud con las condiciones parlamentarias en las que tuvo que desenvolverse Unión de Centro Democrático, entre 1977 y 1982, y el PSOE, de 1993 y 1996 y desde 2004 a 2011, como se observa en el Gráfico $2 .^{10}$

El concepto de partido "fuerte" no implica que sea, necesariamente, el partido con un mayor contingente parlamentario. Estos partidos, que incluyen al legislador medio en el parlamento, suelen estar muy próximos también al votante medio, como se desprende de las propias posiciones atribuidas a los partidos en distintos estudios de opinión pública, y pueden representar mejor a este que los gobiernos basados en coaliciones mayoritarias, que desplazan el centro de gravedad hacia un lado del espectro político (Strom, 1990: 244). A comienzos de 1977, la posición media del electorado en la escala izquierda-derecha y 1 a 10 se situaba en 5,53, mientras que la posición atribuida a UCD en 1978 por sus votantes era de 5,63 y de 5,74 por el conjunto de los electores con unas preferencias partidistas definidas; los que no expresan una preferencia determinada lo situaban en el 6,06, un dato que supone que el conjunto del electorado considera el 5,96 como posicionamiento espacial de UCD. En 1993, el PSOE pudo formar un gobierno minoritario, ocupando el punto 4,2 en la escala de autoubicación del electorado, cuyo votante medio estaba situado, en aquellos momentos, en el 4,7; el PP, principal grupo de la

10 Los gráficos se han elaborado a partir de las posiciones en el espacio y ubicación de los partidos españoles, que resultan de distintos estudios del CIS. Para los datos en 2008, estudio $\mathrm{n}^{\circ} 2.750$, Pre-electoral Elecciones Generales y al Parlamento de Andalucía, 2008, enero-febrero 2008, preg. 32; estudio $\mathrm{n}^{\circ} 2.757$, Post-electoral Elecciones Generales y al Parlamento de Andalucía, 2008, marzo-abril 2008, preg. 47. Para los datos de 2016, estudio $\mathrm{n}^{\mathrm{o}} 3.145$, Postelectoral elecciones generales 2016, julio 2016, pregs. 36, 41. Otros modelos espaciales similares podrían haberse desarrollado a partir de la ubicación ideológica derivada de distintos paneles de expertos, como el Manifesto Project, la encuesta de Chapel Hill y otros estudios, pero la disponibilidad de estos datos en largas series temporales y su actualización permanente hacen más adecuados y comparables entre sí los datos procedentes de los estudios del CIS. 
oposición era percibido posicionalmente por los electores en un extremo del espectro político, en la posición 8,2. Los Gobiernos minoritarios sustantivos de Rodríguez Zapatero I y II, de 2004 a 2011, se formaron con el PSOE ubicado, tanto en 2004 como en 2008, en posiciones muy próximas (4,04 en 2008) a las del votante medio $(4,65)$. Tal vez, por eso, según los estudios del CIS, el electorado prefería un gobierno en minoría del PSOE (el 35\%) en lugar de coaliciones con los nacionalistas $(13,7 \%)$ o con la izquierda $(22,1 \%){ }^{11}$

Gráfico 2. Gobierno minoritario del PSOE, en equilibrio, con un winset vacío (2008)

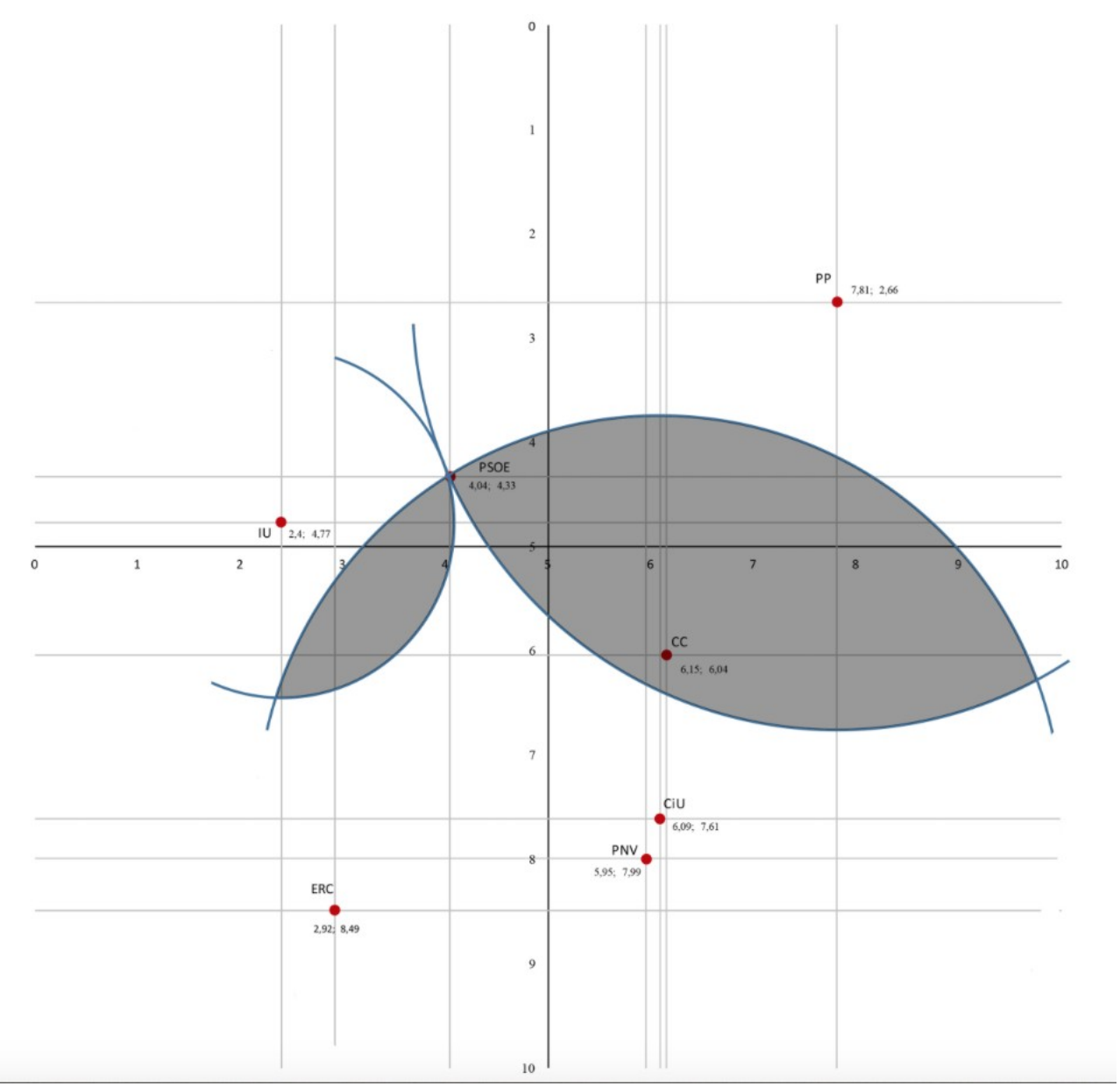

Fuente: elaboración propia.

Como ya hemos apuntado, si el primer partido está lejos de la mayoría absoluta, la importancia de la ubicación espacial para la viabilidad y/o la estabilidad de un gobierno minoritario aumenta. Ello explica que el único formateur en la legislatura fallida de 2016 fuera el líder del PSOE, Pedro Sánchez. Otro buen ejemplo es el

11 También han sido objeto de análisis las preferencias y las percepciones públicas de los distintos tipos de gobierno (Vowles, 2010; Vázquez y Delgado, 2013). 
gobierno Rajoy II, formado en 2016, que era un gobierno minoritario vulnerable, puesto que no podía vetar o impedir la formación de otros gabinetes alternativos; por ejemplo, un gobierno constituido por PSOE y Podemos, con el apoyo de grupos nacionalistas de la cámara, que es la coalición de partidos que, en junio de 2018, apoyó la primera moción de censura exitosa en la historia del parlamentarismo español (Gráfico 3).

Gráfico 3. Gobierno minoritario del PP, con un winset no vacío (2016)

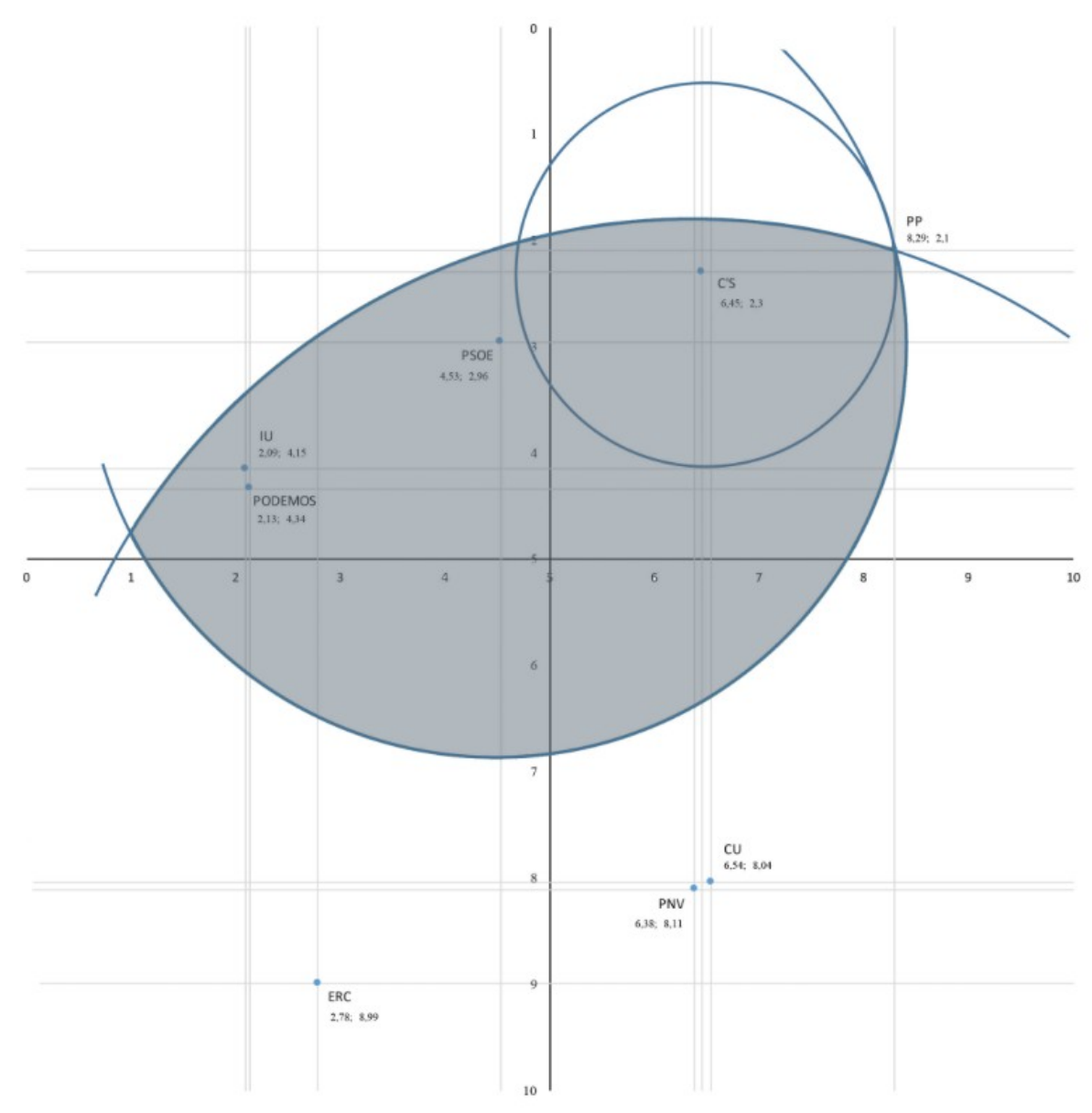

Fuente: elaboración propia.

En la legislatura 2016-2019, el PNV ocupaba la posición del legislador medio y las principales formaciones políticas, PP y PSOE, no estaban situadas en posiciones muy distintas de las que habían venido ocupando en periodos anteriores. Sin embargo, la emergencia de nuevos partidos en el Congreso de los Diputados había acabado por alterar la geometría de los gobiernos minoritarios españoles, mostrando, como señala $\mathrm{H} 1$, que la probabilidad de que un Gobierno minoritario 
vete a todos los demás posibles gabinetes alternativos es más alta si el Gobierno está situado en la posición media del Parlamento que si no ocupa una posición central en el espacio, como sucedía con el gabinete Rajoy II. De modo que los partidos centrales, fuertes o nucleares, desde el punto de vista de la viabilidad de los gobiernos, tienden a formar gobiernos menos vulnerables y menos probables a ser sustituidos por otros gobiernos, de acuerdo a lo planteado por $\mathrm{H} 1$.

Gráfico 4. Gobierno minoritario del PSOE, en equilibrio, con un winset vacío (2018)

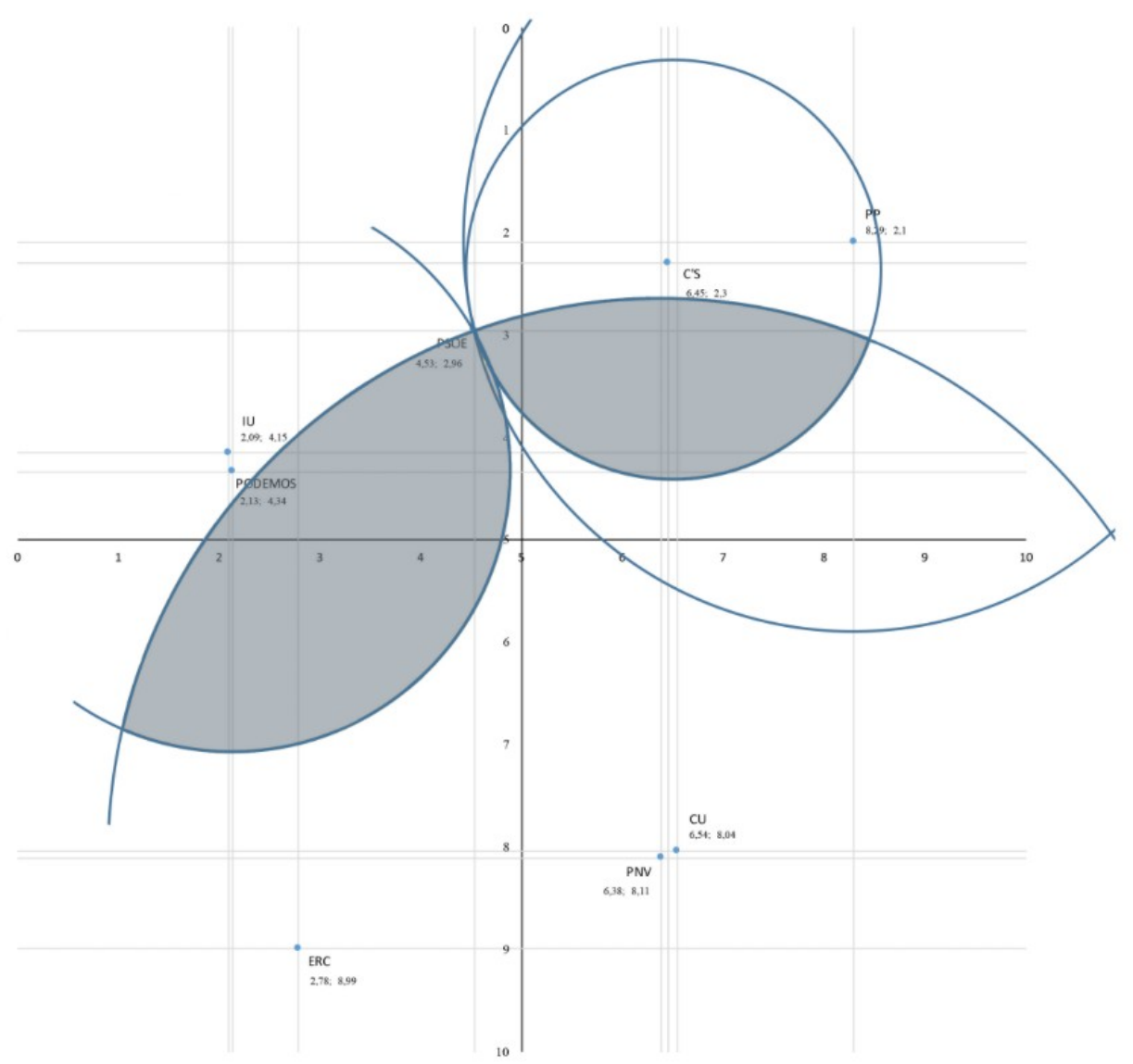

Fuente: elaboración propia.

Por esta razón, un gobierno minoritario del PSOE, con Pedro Sánchez de presidente, pudo derrotar al gobierno en minoría del PP y una vez establecido, con el apoyo del partido que contenía al legislador medio, el PNV, podía vetar cualquier gobierno de coalición incluido en sus pétalos, ya que en todos ellos el PSOE era un aliado imprescindible, como se observa en el Gráfico 4. 


\section{Políticas: la efectividad de los gobiernos minoritarios sustantivos}

Aunque hemos abordado las circunstancias que rodean la viabilidad y estabilidad de los gobiernos minoritarios, aún no hemos tratado su capacidad potencial para proporcionar soluciones a las demandas que reciben en forma de políticas públicas. En esta sección, nos ocuparemos de la capacidad de los gobiernos minoritarios españoles para ser efectivos en el cumplimiento de su agenda legislativa, una cuestión que parece mejor explicada desde la perspectiva de los partidos en términos de "policy seeking", como buscadores de políticas.

En España todos los gobiernos han sido monocolores y han sido apoyados o, al menos tolerados, por una mayoría parlamentaria. Los gobiernos mayoritarios han podido impulsar, sin obstáculos, su agenda política y legislativa (Calvet Crespo, 2003). Los gobiernos minoritarios también han podido gobernar sin grandes dificultades, al menos cuando el nivel de fragmentación parlamentaria era más reducido, antes del ciclo electoral de 2015/2016 pues, desde un punto de vista estructural (por su composición) y funcional (esto es, compartiendo características y exhibiendo pautas de ruptura, de rendimiento electoral y de alternancia) estos gobiernos minoritarios habían sido más semejantes a los "gobiernos de partido mayoritario imperfecto" que a los "gobiernos de coalición" (Strom, 1990: 61, 238). Este argumento encuentra especial apoyo en el caso de los gobiernos minoritarios unipartidistas al estilo de los formados por UCD, PSOE y PP que, además de muy frecuentes en la práctica, habían sido hasta 2015, estructuralmente, similares a los gobiernos unipartidistas mayoritarios (Tabla 4). Así, si el 98,9\% de la legislación aprobada bajo gobiernos mayoritarios ha tenido un origen gubernamental, esta tasa ha sido del $88,7 \%$ de las iniciativas legislativas aprobadas bajo gobiernos minoritarios (Garrido, 2019: 516). En segundo lugar, si se analizan las tasas de aprobación de los proyectos de ley aprobados por gobiernos mayoritarios hay una brecha similar: el $88,8 \%$ de las iniciativas gubernamentales bajo gabinetes mayoritarios fueron aprobadas frente al 77,5\% de las iniciativas de los gabinetes minoritarios; algunos estudios que no analizan la producción legislativa de los primeros gobiernos de UCD o las últimas legislaturas, con un parlamento más fraccionado, encuentran incluso tasas similares entre gobiernos mayoritarios y minoritarios, del 88,6\% frente al 87,8\%, respectivamente (Field, 2016: 79).

Lo mismo sucede en otros sistemas parlamentarios europeos homologables al español. Los datos comparados muestran que el grado de legislación de origen gubernamental no se ha visto, especialmente, alterada por razón del tipo de gobierno.

Ello se debe, desde las teorías posicionales acerca de los gobiernos minoritarios, a que el partido que sostiene al Ejecutivo suele estar situado centralmente en el espacio político, lo que le permite elegir sus apoyos según la naturaleza de los proyectos legislativos. George Tsebelis (1995) analizó teóricamente, desde una perspectiva espacial, los casos en que las preferencias de un gobierno minoritario con posiciones centristas y de la mayoría de la asamblea no coinciden concluyendo que "si un gobierno minoritario está centralmente situado en el espacio puede formar parte de muchas posibles mayorías parlamentarias y, en consecuencia, mover el status quo dentro de su propio winset" por lo que, teórica y políticamente, "la mayor parte el tiempo no tendría por qué comprometerse en absoluto y podría conseguir un resultado final sobre su punto ideal", según la disposición mostrada en el Gráfico 5. 
Gráfico 5. Gobierno parlamentario centrista en un espacio legislativo bidimensional

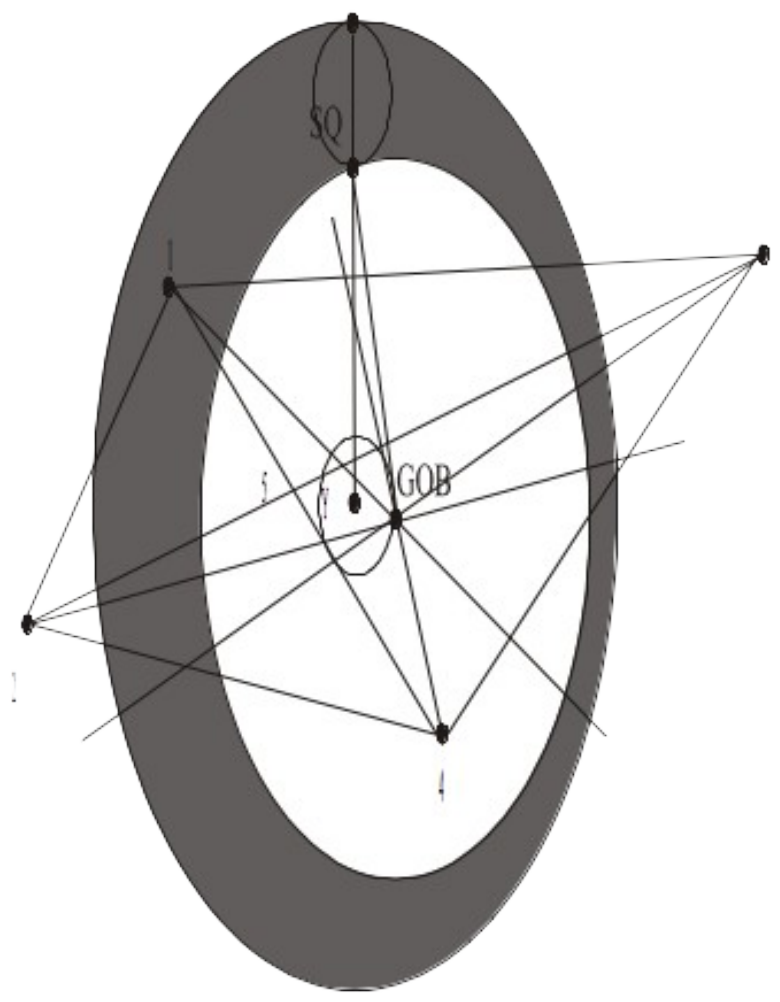

Fuente: elaboración propia.

Un gobierno minoritario situado centralmente en el espacio, como los distintos ejecutivos formados por Unión de Centro Democrático, entre 1977 y 1982, y PSOE, entre 2004 y 2008, puede convertir en más favorable el status quo moviéndolo a cualquier punto dentro de su propio winset meramente cambiando de aliado en la asamblea según el tipo de política que desee aprobar (Maurer, 2008). En el parlamento español, en estas legislaturas no existía una mayoría sin el apoyo de UCD o PSOE, excepto en el caso de que los restantes partidos hubiesen decidido unirse para derrotar al Ejecutivo, aunque resulta difícil imaginar que partidos opuestos -ideológica y programáticamente- pudieran alcanzar compromisos para tomar decisiones importante al margen del partido más numeroso de la cámara. Kaare Strom (1990: 78) resumió muy bien esta situación, incluso, en términos espaciales: "En un espacio unidimensional los gabinetes minoritarios deberían tender a ser gobiernos del centro con opciones bipolares. A causa de su localización estratégica en el centro político (quizás en el core) dichos gabinetes deberían ser capaces de dividir y dominar a la oposición."

De hecho, desarrollando el planteamiento de Strom, cuanto menor sea la distancia que separa al gabinete del "yolk" de la asamblea, como ilustra esta figura, más insignificante resultará la diferencia entre la mayoría gubernamental y la legislativa, teórica y políticamente; cuando la distancia entre el gabinete y el centro del "yolk" es más pequeña que el diámetro del "yolk" las preferencias del ejecutivo y del 
parlamento coincidirán y el resultado del proceso legislativo se localizará sobre el punto ideal del gobierno. ${ }^{12}$ De este modo, la mayoría de las cuestiones que los gobiernos de Suárez o Zapatero preferían sobre el status quo en cada una de las políticas generales y sectoriales en las que tuvo que tomar decisiones legislativas fueron aprobadas por el parlamento.

Podemos mostrar esta situación bajo los gobiernos minoritarios sustantivos Zapatero I y II, confirmando H2. Como ha señalado Field (2016: 195), "en un parlamento de 350 diputados, el partido central ocupa el escaño 176 (técnicamente el 175,5). En 2008 había 8 diputados de partidos situados a la izquierda del PSOE. En consecuencia, los 169 diputados de este último ocupaban los escaños 9 a 177. Los diputados restantes pertenecían a partidos situados a la derecha del PSOE. Por otra parte, había 155 diputados de partidos que defendían posiciones más centralistas. En consecuencia, los 169 diputados del PSOE ocupaban los escaños 156 a 324. Por lo tanto, el PSOE ocupaba el escaño central en ambas dimensiones. Aunque las cifras son distintas, los socialistas también ocupaban el escaño central en el parlamento de 2004." Esta posición de centralidad aumenta la efectividad legislativa del gobierno, de acuerdo a lo sugerido por $\mathrm{H} 2$, a veces incluso cambiando de manera progresiva o paulatina los principales partidos de apoyo a medida que avanzaba la legislatura. ${ }^{13}$

El Gráfico 8 representa el parlamento español en 2008 con sus cinco grupos políticos más relevantes ubicados en un espacio bidimensional. ${ }^{14}$ Un partido situado en la intersección de las dos diagonales del cuadrángulo IU-ERC-CiU-PP, necesariamente, sería parte integrante de cualquier mayoría que pudiera formarse y, cambiando sus alianzas según la naturaleza de las medidas legislativas a adoptar, obtendría la base de apoyo parlamentaria apropiada para conseguir resultados muy cercanos a sus preferencias ideales. El gobierno de Zapatero, aun no ocupando exactamente la intersección de las dos diagonales, el "core" del parlamento, se situaba dentro del cuadrángulo en una posición próxima al "yolk" de la asamblea Gráfico 6).

12 El "core" de un parlamento, en un espacio multidimensional, es "equivalente a la posición media en un eje unidimensional". El "yolk" es la "esfera más pequeña que intersecta con todos los hiperplanos medios" (Tsebelis, 1995: 91, n. 11). Los hiperplanos medios son hiperplanos (planos en más de dos dimensiones) que separa en dos grupos a los votantes de modo que una mayoría de votantes están sobre el hiperplano o a un lado o a otro lado de este. El cálculo de win sets y el desarrollo de conceptos como el "yolk" ha permitido un gran desarrollo en la metodología de la teoría espacial de la política (Miller, Grofman y Feld, 1989; Tsebelis, 2002).

13 Una dinámica que puede aparecer en los contextos de "geometría variable" es el cambio progresivo o paulatino de los principales partidos de apoyo a medida que avanza la legislatura. En el caso del gobierno Zapatero I, ERC era uno de los principales aliados del gobierno a comienzos de la legislatura 2004-2008 pero se fue diluyendo hasta casi difuminarse su alianza con el partido gubernamental al final de la misma, siendo paulatinamente sustituido por algunas de los restantes grupos nacionalistas, como el PNV y el BNG, que, precisamente, se habían abstenido en la investidura del presidente en 2004 (Field, 2016: 111-115).

14 La metodología aplicada en este apartado, aunque deriva de los seminales estudios sobre el poder de agenda en juegos de votación multidimensionales y la secuencia de decisiones para superar el problema de intransitividad de la regla de la mayoría de McKelvey o Schofield, está basada en el análisis espacial de veto players de George Tsebelis, que presenta un modelo completo tanto para veto players individuales como colectivos (Tsebelis, 2002: 17-63). Estudios similares, que explican determinados conceptos (win set, yolk, core, etc.) de la metodología utilizada en este apartado, son los de Miller, Grofman y Feld (1989); Miller y Hammond, 1990; McCarty, Pole y Rosenthal; Snyder y Groseclose (2001), etc. 
Gráfico 6. Winset del Gobierno minoritario del PSOE en un espacio bidimensional, 2008

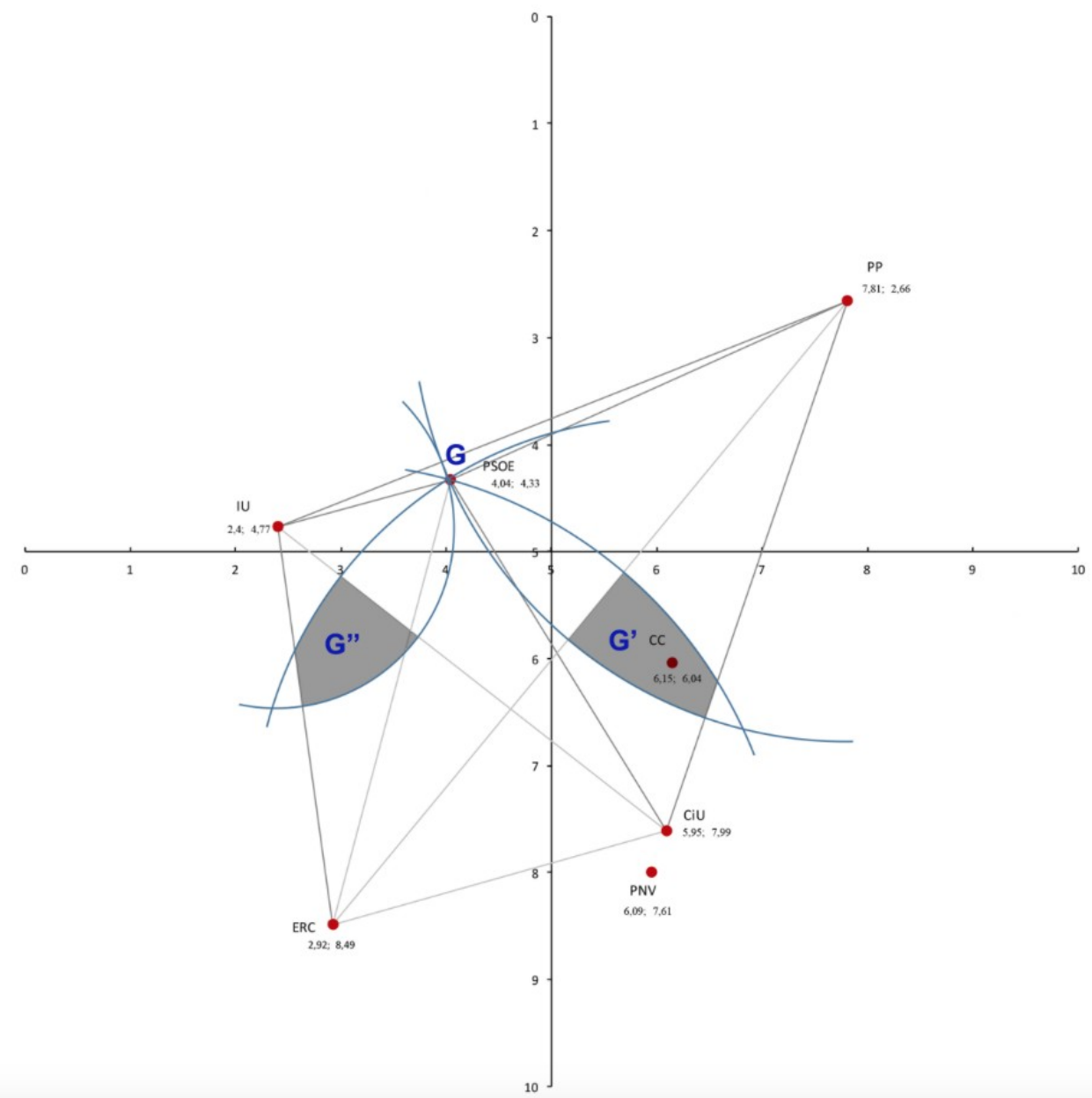

Fuente: elaboración propia.

Desde un punto de vista formal si el Gobierno $(G)$ está situado en una posición próxima a la intersección de las dos diagonales $(\mathrm{C})$ del cuadrángulo formado por el resto de los partidos relevantes (PP, IU, ERC y CiU) las posibilidades son las siguientes (Tsebelis, 1995: 99):

a) Si el status quo se encontraba situado fuera del cuadrangulo PP-IU-ERC-CiU el Gobierno siempre podía congregar una mayoría que prefería el punto ideal del Ejecutivo (G) al status quo.

b) $\mathrm{Si}$ el status quo estaba localizado dentro del triángulo PP-ERC-CiU los miembros de la coalición legislativa del Gobierno podían ser IU y ERC ó (incluso, aunque más improbable) PP. Con esta alianza el Gobierno podía mover el status quo hacia su punto ideal, excepto cuando el status quo estaba situado en el área de intersección entre las curvas de indiferencia de ERC y PP (G'), caso en 
el que sólo podía conseguir un nuevo status quo más próximo a su punto ideal pero no situarlo sobre éste.

c) Si el status quo estaba situado dentro del triángulo IU-ERC-CiU los aliados del Gobierno para un cambio en el status quo, ante la dificultad de conseguir el apoyo del PP, debían ser forzosamente IU y CiU. Con esta coalición el Gobierno podrá conseguir un cambio del status quo y situarlo sobre su punto ideal, salvo que aquel se hubiese encontrado dentro del área de intersección de IU y CiU (G', ), en cuyo caso el Gobierno podía obtener un nuevo status quo más próximo a su punto ideal, aunque no dicho punto exactamente.

d) Si el status quo estaba situado dentro del triángulo PP-IU-G, un espacio mucho más reducido, como se ve en el Gráfico, el Gobierno podía formar una coalición con ERC y CiU y cambir el status quo por su propio punto ideal.

e) Solo si el status quo estaba situado en el área PP-C-IU-G, el Gobierno se encontraba en minoría, puesto que podían formarse dos mayorías legislativas excluyendo al gabinete (PP-ERC-CiU y IU-ERC-CiU). Se trata de la única situación en la que la voluntad del Gobierno y la de la cámara hubieran podido diferir, teóricamente, si estas coaliciones hubieran superado el número de escaños controlado por el Gobierno (169), lo que no era el caso, pues la segunda sumaba apenas unos pocos escaños y la primera sumaba 167; aunque esta primera coalición, incluyendo al PNV, hubiera podido sumar 173 escaños, e incluso considerando al PNV y excluyendo a ERC hasta 170.

La importancia de bloquear el apoyo de PNV y CiU explicaría que los índices de coincidencia en las votaciones parlamentarias entre 2008 y 2011 fuera máxima en el caso del PNV (desde 99,0 en 2008 a 87,8 en 2010) o CC (89,1 en 2009 y 92,3 en 2010) y experimentara un aumento por lo que respecta a $\mathrm{CiU}$ (hasta 75,3 en 2011), que acabó con un índice similar al PNV, principal partido de apoyo en esta legislatura (Field, 2016: 117-118).

Así, estos gobiernos, que constituyen casos paradigmáticos de "geometría variable", pudieron desarrollar la típica estrategia de alianzas cambiantes (shifting majorities) y coaliciones ad hoc: "Negociando separadamente cada cuestión sobre una base ad hoc, el típico gobierno minoritario puede en cada caso escoger al compañero de coalición menos «costoso» disponible. Esto es especialmente beneficioso si hay muchos posibles aliados para formar la coalición, si diferentes dimensiones políticas tienen diferente importancia para los distintos partidos de la oposición, y si sus funciones de utilidad entre cargos y políticas difieren... Cuanto más fuerte sea el gobierno mayor será la tendencia a las coaliciones cambiantes." (Strom, 1990: 108-109).

Los gobiernos minoritarios sustantivos formados en España después de 2016, sin embargo, no han sido tan exitosos ni tan efectivos desde el punto de vista legislativo. En el caso del gobierno Rajoy II, la posición no central del PP en el Congreso de los Diputados, lo obligó a buscar un pacto de legislatura con Ciudadanos, que, en todo caso, aún no era suficiente para alcanzar una mayoría de escaños. Esta "geometría estable" debía ser complementada con el apoyo puntual de partidos nacionalistas o regionalistas, como el $\mathrm{PNV}$ y $\mathrm{CC}$, o, incluso, en alguna votación esporádica, del PDeCAT. Sin embargo, a partir del otoño de 2017, esta geometría se hizo, forzosamente, "estable", puesto que sólo la suma de $\mathrm{PP}+\mathrm{C}$ 's $+\mathrm{PNV}+\mathrm{CC}$ 
proporcionaba el control de una mayoría absoluta de los escaños al Gobierno. En este escenario, incluso los partidos de apoyo se permitieron distintos grados de oposición y diferentes propuestas gubernamentales fueron derrotadas en el parlamento.

Gráfico 7. Winset del Gobierno minoritario del PP, 2016, en un espacio bidimensional

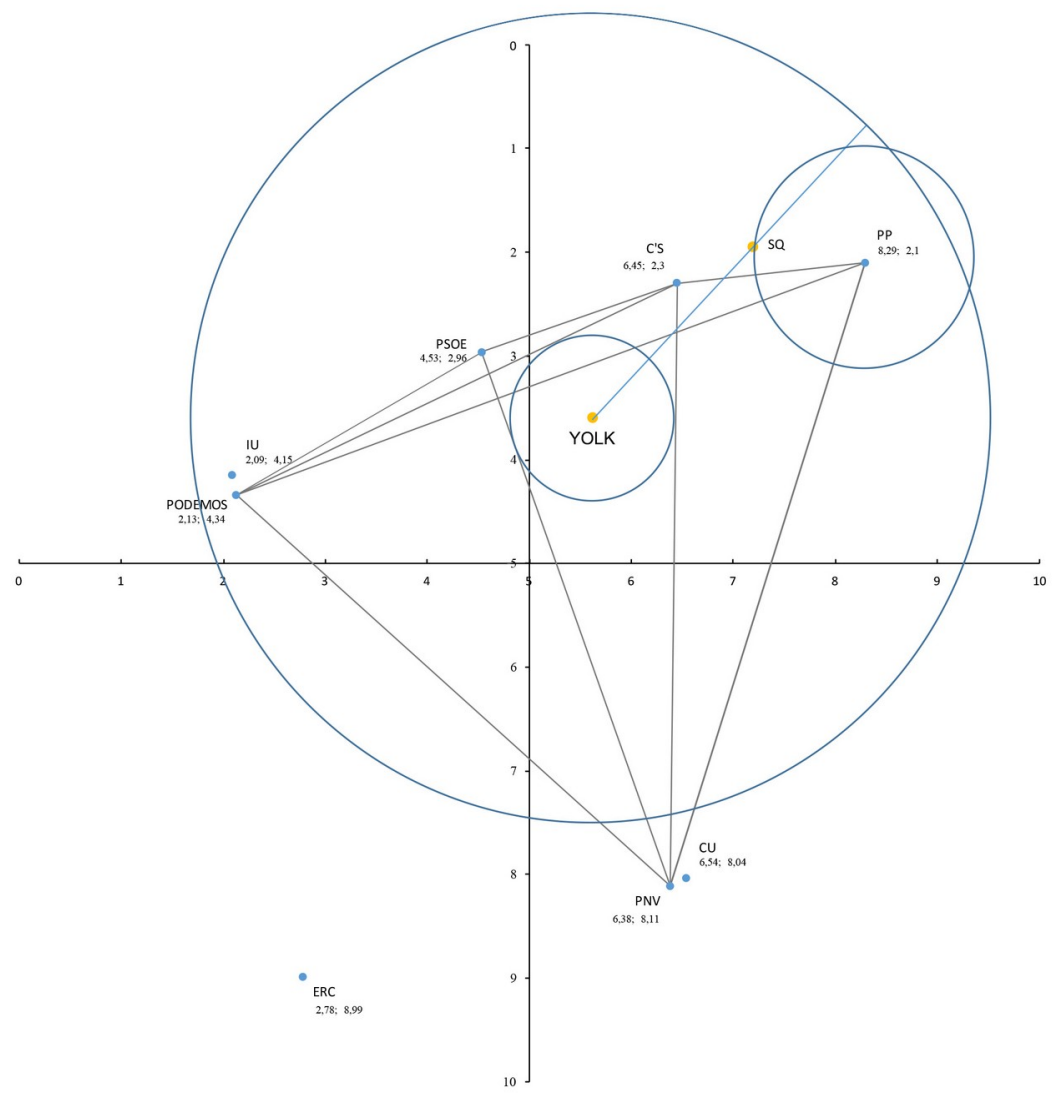

Fuente: elaboración propia.

Se puede argumentar que, al aumentar considerablemente la fragmentación parlamentaria, como consecuencia de las elecciones de 2016, el winset del SQ del Partido Popular, que gobernaba con un gabinete minoritario sustantivo, era muy pequeño respecto al winset del SQ del Congreso de los Diputados, como muestra el Gráfico 7, confirmando H2. Además, puede observarse, en el mismo Gráfico, que el partido del gobierno está fuera del cuadrángulo formado por el resto de las formaciones políticas (Ciudadanos, PSOE, Podemos y PNV) y no dentro, evidenciando que no es un partido central, como lo eran la UCD o el PSOE en los gobiernos minoritarios sustantivos de "geometría variable" de Suárez o Zapatero. 
En cambio, el winset del SQ de un gobierno socialista en minoría era mucho mayor y estaba recogido dentro del winset del SQ del Congreso, como se puede comprobar en el Gráfico 8, lo que quiere decir que, en condiciones estables, podría haber generado propuestas políticas aceptables por distintas mayorías parlamentarias. Sin embargo, este gabinete aunque está próximo al "yolk" y al "core" del parlamento, también se encuentra situado fuera del cuadrángulo de las principales fuerzas políticas (PP, Ciudadanos, Podemos y PNV). El gobierno Sánchez I era un gobierno minoritario sustantivo, también forzosamente de "geometría estable", ya que, pese a su posición más central que el del PP, se vio abocado a hacer un uso creciente de decretos-leyes y a aprobar todas sus propuestas legislativas con los mismos partidos de apoyo que habían sido la base de la moción de censura de junio de 2018, con muy escaso margen para el cambio de aliados y, por tanto, con un limitado poder de negociación. De hecho, su deficiente output legislativo se debe a que parte de su coalición de apoyo para la censura no apoyaba su continuidad como gabinete, en el entendido de que debía convocar elecciones anticipadas y no actuar como gobierno en minoría; esta divergencia fundamental con sus aliados ponen en duda, tanto su carácter de gobierno "viable" como "estable", por lo que, dado su diferente origen respecto al resto de gabinetes constituye un caso claramente aparte.

De hecho, dada la fragmentación y la polarización de la legislatura 2016-2019, fue muy compleja la búsqueda de pactos parlamentarios regulares, continuados y de "geometría variable" para el gobierno Sánchez I: en primer lugar, existía un veto cruzado entre C's y Podemos, lo que impedía coaliciones alternantes entre un gobierno en minoría del PSOE y ambos partidos y, por supuesto, coaliciones que incluyeran a los tres grupos; en segundo lugar, la situación derivada del procesamiento de distintos líderes independentistas catalanes, había hecho a estos más reacios a apoyar políticas, como el proyecto de presupuestos generales del Estado en 2019, sin concesiones sobre las reivindicaciones principales de estas fuerzas nacionalistas (Nohlen y Garrido, 2020: 166-169). Esta doble circunstancia impidió gobernar a un gabinete en minoría que, en una situación de menor radicalización y antagonismo entre las fuerzas políticas, hubiera permitido la gobernabilidad con un gobierno minoritario del segundo partido de la cámara haciendo pactos ad hoc con fuerzas a su izquierda (Podemos), a su derecha (C's) y con el resto de formaciones políticas de carácter nacionalista o regionalista. En este contexto, era imposible el desarrollo de lo que Strom (1990: 97, 105) denomina "bundling strategies" ("estrategias de empaquetado"), típico de la geometría variable, con alianzas parlamentarias cambiantes (shifting majorities), alrededor de diferentes paquetes de políticas sectoriales, como en los gobiernos Zapatero I y II (Field, 2009 y 2016: 115). ${ }^{15}$

15 Este tipo de acuerdos son similares, aunque menos formalizados, que los "Forligs" daneses (Christiansen y Damgaard, 2008: 80), acuerdos legislativos entre el gobierno minoritario y ciertos partidos de la oposición alrededor de determinadas materias concretas. Por ejemplo, los acuerdos entre la coalición minoritaria liberal-conservadora y el Partido Popular danés para su respaldo de la posición del gobierno sobre la reforma municipal y la guerra en Irak a cambio de ciertas concesiones en materia migratoria. 
Gráfico 8. Winset del Gobierno minoritario del PSOE, 2018, en un espacio bidimensional

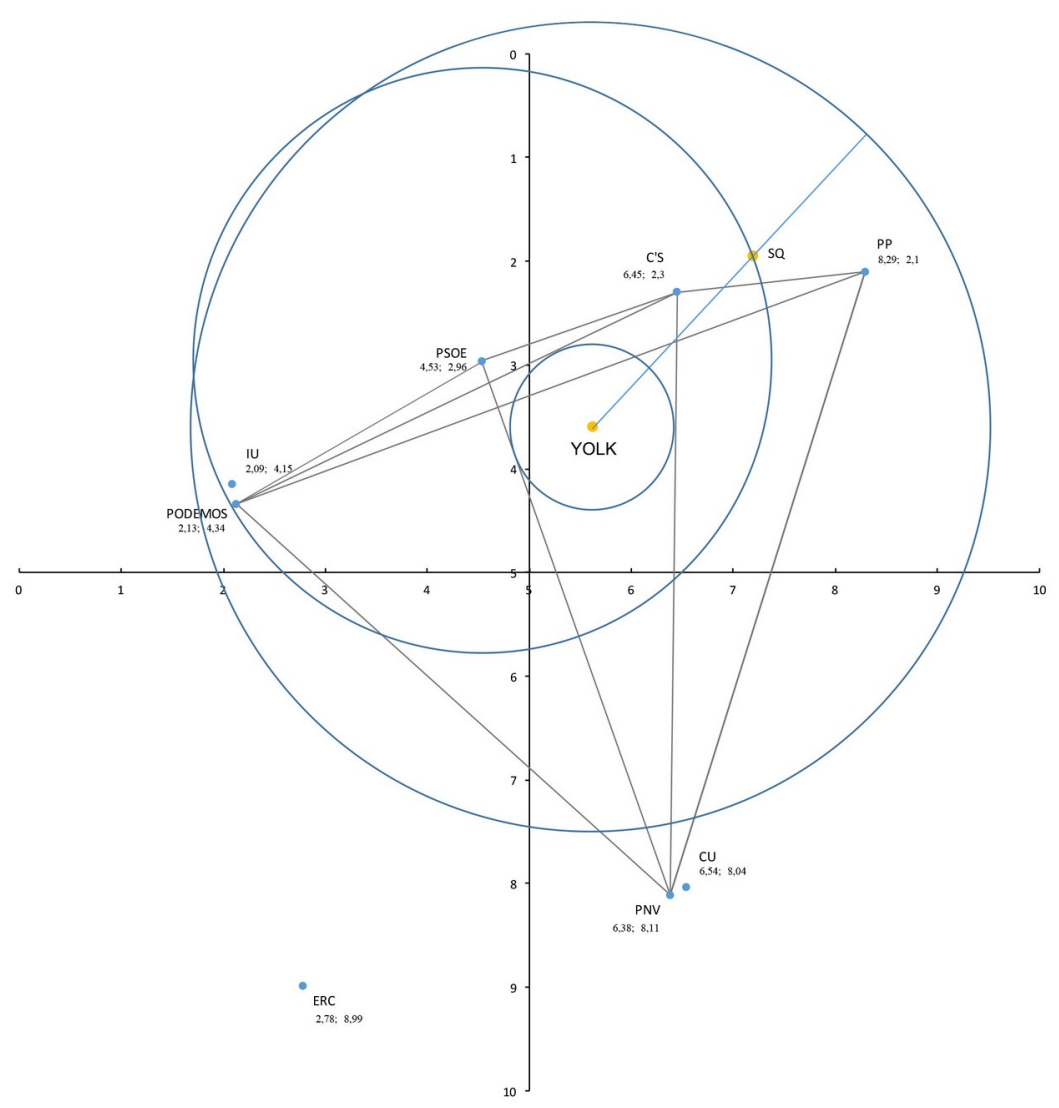

Fuente: elaboración propia.

Excluyendo a los gobiernos de la transición y a este último gobierno Sánchez I, peculiar porque ha sido el primero en tener su origen en una votación de censura, y que no ha gozado del apoyo de sus colaboradores en el triunfo de la misma ni para gobernar ni para aprobar sus propios presupuestos, la evidencia empírica, que recogen las tablas 4 y 5 confirman las predicciones del modelo.

La tasa de éxito de los gobiernos es mayor en los gobiernos minoritarios formales $(87,9 \%)$ que en los gobiernos minoritarios sustantivos $(82,3 \%)$, siendo también muy diferente esta tasa para los gobiernos sustantivos de geometría variable de Zapatero (86,5\%) -casi similares a los gobiernos minoritarios formales- y para el gobierno sustantivo de geometría estable de Rajoy (73,9\%), de acuerdo a la predicción. Lo mismo sucede con la tasa de participación del gobierno en la legislación aprobada: el 88,8 de los gobiernos minoritarios formales por el porcentaje, muy similar, del $86,6 \%$ de los gobiernos minoritarios sustantivos de 
geometría variable, a diferencia del 47,2\% del gobierno minoritario sustantivo de geometría estable.

Tabla 4. Proyectos de ley y proposiciones de ley aprobadas según tipo de gobierno

\begin{tabular}{|c|c|c|c|c|c|c|c|c|c|c|c|}
\hline \multirow[t]{2}{*}{ Gobiernos } & \multicolumn{3}{|c|}{ Iniciativa Gobierno } & \multicolumn{3}{|c|}{ Iniciativa Legislativo } & \multicolumn{2}{|c|}{ Participación } & \multirow[t]{2}{*}{ Otros } & \multicolumn{2}{|c|}{ Decretos Leyes } \\
\hline & Present. & Aprob & $\begin{array}{c}\% \\
\text { Éxito }\end{array}$ & Present. & Aprob. & $\begin{array}{c}\% \\
\text { Éxito }\end{array}$ & $\begin{array}{c}\% \\
\text { Ejecut. }\end{array}$ & $\begin{array}{c}\% \\
\text { Legisl }\end{array}$ & & Present. & Aprob \\
\hline González I & 205 & 183 & 89,3 & 106 & 12 & 11,3 & 93,8 & 6,2 & 3 & 40 & 40 \\
\hline González II & 125 & 108 & 86,4 & 141 & 10 & 7,1 & 91,5 & 8,5 & 3 & 20 & 20 \\
\hline González III & 128 & 101 & 78,9 & 154 & 16 & 10,4 & 86,3 & 13,7 & 1 & 30 & 30 \\
\hline Aznar II & 175 & 170 & 97,1 & 369 & 18 & 4,9 & 90,4 & 9,6 & 13 & 42 & 42 \\
\hline Rajoy I & 163 & 160 & 98,2 & 278 & 9 & 3,2 & 94,7 & 5,3 & 41 & 76 & 76 \\
\hline Media & 159,2 & 144,4 & 90,0 & 209,6 & 13,0 & 7,4 & 91,4 & 8,6 & 12,2 & 41,6 & 41,6 \\
\hline \multicolumn{12}{|c|}{ Gobiernos minoritarios } \\
\hline Suárez & 174 & 111 & 63,8 & 71 & 9 & 12,7 & 92,5 & 7,5 & - & 63 & - \\
\hline $\begin{array}{l}\text { Suárez II y } \\
\text { C. Sotelo }\end{array}$ & 342 & 237 & 69,3 & 193 & 28 & 14,5 & 89,4 & 10,6 & - & 102 & - \\
\hline González IV & 130 & 112 & 86,2 & 83 & 14 & 16,9 & 88,9 & 11,1 & 3 & 40 & 40 \\
\hline Aznar I & 192 & 172 & 89,6 & 283 & 22 & 7,8 & 88,7 & 11,3 & 5 & 85 & 85 \\
\hline Zapatero I & 152 & 139 & 91,4 & 308 & 21 & 6,8 & 86,9 & 13,1 & 22 & 52 & 51 \\
\hline Zapatero II & 147 & 120 & 81,6 & 330 & 19 & 5,8 & 86,3 & 13,7 & 23 & 56 & 56 \\
\hline $\begin{array}{l}\text { Rajoy } \\
\text { (funciones) }\end{array}$ & - & - & - & 39 & 0 & 0,0 & - & - & - & 2 & 2 \\
\hline Rajoy II & 23 & 17 & 73,9 & 249 & 19 & 7,6 & 47,2 & 52,8 & 21 & 30 & 29 \\
\hline Sánchez I & 26 & 1 & 3,8 & 127 & 0 & 0,0 & 100,0 & 0,0 & 4 & 35 & 10 \\
\hline Media & 148,3 & 113,6 & 70,0 & 187,0 & 14,7 & 8,0 & 85,0 & 15,0 & 13,0 & 51,7 & 39,0 \\
\hline
\end{tabular}

Fuente: Maurer, 2008: 55, 57, 60; Field, 2016: 133; Del Campo y García Montero, 2018; y datos actualizados por los autores. En el caso de la iniciativa legislativa, los datos relativos a la XII Legislatura incluyen las Proposiciones de Ley de los Grupos Parlamentarios del Congreso, del Senado, de los diputados y de los Parlamentos autonómicos. 
Tabla 5. Votaciones de presupuestos por tipos de gobierno mayoritarios y minoritarios (1983-2019)

\begin{tabular}{|c|c|c|c|c|c|c|c|c|c|}
\hline & $\begin{array}{c}\text { Año } \\
\text { Presupuesto }\end{array}$ & $\begin{array}{l}\text { Fecha debate } \\
\text { Enmienda } \\
\text { a la totalidad }\end{array}$ & $\begin{array}{l}\text { Votos } \\
\text { a favor }\end{array}$ & \begin{tabular}{|c|} 
Votos \\
en contra
\end{tabular} & Abstenciones & $\begin{array}{c}\text { Votos } \\
\text { emitidos }\end{array}$ & $\begin{array}{c}\% \text { Rechazo } \\
\text { sobre } \\
\text { presentes }\end{array}$ & $\begin{array}{c}\text { \% Rechazo } \\
\text { sobre } \\
\text { composición }\end{array}$ & $\begin{array}{l}\text { Diferencia } \\
\text { "a favor" } \\
\mathrm{y} \\
\text { "en contra" }\end{array}$ \\
\hline \multicolumn{10}{|c|}{ Gobiernos mayoritarios } \\
\hline \multirow{4}{*}{ 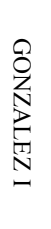 } & 1983 & $18 / 05 / 1982$ & 116 & 181 & 7 & 304 & 59,54 & 51,71 & -65 \\
\hline & 1984 & $27 / 10 / 1983$ & 103 & 178 & 2 & 283 & 62,90 & 50,86 & -75 \\
\hline & 1985 & 08/11/1984 & 97 & 171 & 1 & $269^{*}$ & 63,33 & 48,86 & -74 \\
\hline & 1986 & $30 / 10 / 1985$ & 72 & 179 & 15 & $266^{*}$ & 67,04 & 51,14 & -107 \\
\hline \multirow{3}{*}{ 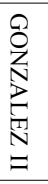 } & 1987 & $30 / 10 / 1986$ & 132 & 176 & 6 & 314 & 56,05 & 50,29 & -44 \\
\hline & 1988 & $27 / 10 / 1987$ & 134 & 182 & 1 & $317^{*}$ & 57,23 & 52,00 & -48 \\
\hline & 1989 & $26 / 10 / 1988$ & 119 & 164 & 0 & 283 & 57,95 & 46,86 & -45 \\
\hline \multirow{4}{*}{ 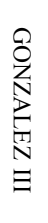 } & 1990 & $28 / 03 / 1990$ & 162 & 172 & 1 & 335 & 51,34 & 49,14 & -10 \\
\hline & 1991 & $30 / 10 / 1990$ & 150 & 171 & 1 & 322 & 53,11 & 48,86 & -21 \\
\hline & 1992 & 24/10/1991 & 138 & 167 & 3 & 308 & 54,22 & 47,71 & -29 \\
\hline & 1993 & $21 / 10 / 1992$ & 152 & 170 & 1 & 323 & 52,63 & 48,57 & -18 \\
\hline \multirow{4}{*}{$\begin{array}{l}\text { 空 } \\
\text { 永 } \\
=\end{array}$} & 2001 & $25 / 10 / 2000$ & 126 & 192 & 2 & 320 & 60,00 & 54,86 & -66 \\
\hline & 2002 & $23 / 10 / 2001$ & 135 & 192 & 1 & 328 & 58,54 & 54,86 & -57 \\
\hline & 2003 & $23 / 10 / 2002$ & 130 & 191 & 0 & 321 & 59,50 & 54,57 & -61 \\
\hline & 2004 & $29 / 10 / 2003$ & 121 & 185 & 14 & 320 & 57,81 & 52,86 & -64 \\
\hline \multirow{6}{*}{ 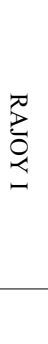 } & 2012 & $25 / 04 / 2012$ & 156 & 182 & 1 & 339 & 53,69 & 52,00 & -26 \\
\hline & 2013 & $24 / 10 / 2012$ & 148 & 179 & 1 & 328 & 54,57 & 51,14 & -31 \\
\hline & 2014 & $23 / 10 / 2013$ & 159 & 182 & 0 & 341 & 53,37 & 52,00 & -23 \\
\hline & 2015 & $22 / 10 / 2014$ & 160 & 184 & 0 & 344 & 53,49 & 52,57 & -24 \\
\hline & 2016 & $26 / 08 / 2015$ & 151 & 185 & 1 & 337 & 54,90 & 52,86 & -34 \\
\hline & & Tedia & 133,1 & 179,2 & 2,9 & 320,6 & 57,1 & 51,2 & $-46,1$ \\
\hline \multicolumn{10}{|c|}{ Gobiernos minoritarios } \\
\hline \multirow{3}{*}{ 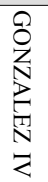 } & 1994 & $21 / 10 / 1993$ & 157 & 178 & 5 & 340 & 52,35 & 50,86 & -21 \\
\hline & 1995 & $26 / 10 / 1994$ & 158 & 177 & 1 & 336 & 52,68 & 50,57 & -19 \\
\hline & 1996 & $25 / 10 / 1995$ & 183 & 158 & 1 & 342 & 46,20 & 45,14 & 25 \\
\hline
\end{tabular}




\begin{tabular}{|c|c|c|c|c|c|c|c|c|c|}
\hline & $\begin{array}{c}\text { Año } \\
\text { Presupuesto }\end{array}$ & $\begin{array}{l}\text { Fecha debate } \\
\text { Enmienda } \\
\text { a la totalidad }\end{array}$ & $\begin{array}{c}\text { Votos } \\
\text { a favor }\end{array}$ & $\begin{array}{c}\text { Votos } \\
\text { en contra }\end{array}$ & Abstenciones & $\begin{array}{c}\text { Votos } \\
\text { emitidos }\end{array}$ & $\begin{array}{c}\% \text { Rechazo } \\
\text { sobre } \\
\text { presentes }\end{array}$ & $\begin{array}{c}\% \text { Rechazo } \\
\text { sobre } \\
\text { composición }\end{array}$ & $\begin{array}{c}\text { Diferencia } \\
\text { "a favor" } \\
\mathrm{y} \\
\text { "en contra" }\end{array}$ \\
\hline \multirow{4}{*}{ 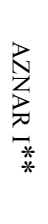 } & 1997 & 23/10/1996 & 161 & 176 & 0 & 337 & 52,23 & 50,57 & -15 \\
\hline & 1998 & 23/10/1997 & 159 & 179 & 2 & 340 & 52,65 & 51,44 & -20 \\
\hline & 1999 & 28/10/1998 & 165 & 175 & 0 & 340 & 51,47 & 50,29 & -10 \\
\hline & 2000 & 26/10/1999 & 151 & 177 & 0 & 328 & 53,96 & 50,86 & -26 \\
\hline \multirow{4}{*}{ 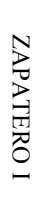 } & 2005 & $27 / 10 / 2004$ & 157 & 180 & 0 & 337 & 53,41 & 51,43 & -23 \\
\hline & 2006 & $26 / 10 / 2005$ & 153 & 183 & 1 & 337 & 54,30 & 52,29 & -30 \\
\hline & 2007 & $17 / 10 / 2006$ & 152 & 177 & 16 & 345 & 51,30 & 50,57 & -25 \\
\hline & 2008 & $24 / 10 / 2007$ & 168 & 177 & 1 & 346 & 51,16 & 50,57 & -9 \\
\hline \multirow{3}{*}{ 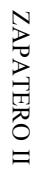 } & 2009 & $22 / 10 / 2008$ & 170 & 177 & 1 & 348 & 50,86 & 50,57 & -7 \\
\hline & 2010 & $21 / 10 / 2009$ & 168 & 177 & 1 & 346 & 51,16 & 50,57 & -9 \\
\hline & 2011 & $20 / 10 / 2010$ & 167 & 177 & 1 & 345 & 51,30 & 50,57 & -10 \\
\hline \multirow{2}{*}{ 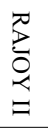 } & 2017 & $04 / 05 / 2017$ & 175 & 175 & 0 & 350 & 50,00 & 50,00 & 0 \\
\hline & 2018 & $26 / 04 / 2018$ & 174 & 176 & 0 & 350 & 50,29 & 50,29 & -2 \\
\hline \multirow{2}{*}{ 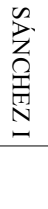 } & 2019 & $13 / 02 / 2019$ & 191 & 158 & 1 & 350 & 45,14 & 45,14 & 33 \\
\hline & \multicolumn{2}{|c|}{ Media } & 165,2 & 175,1 & 1,8 & 342,2 & 51,2 & 50,1 & $-9,9$ \\
\hline
\end{tabular}

Fuente: Elaboración propia a partir del Diario de sesiones del Congreso de los Diputados.

*Hubo 1 Voto nulo.

**La composición del Congreso era de 3.

Análogas diferencias se obtienen observando el apoyo parlamentario a las leyes de presupuestos según el tipo de gobierno, reunido en la tabla 5, que muestra cómo el respaldo es superior en los gobiernos minoritarios sustantivos de geometría variable $(50,93 \%$; en términos absolutos, 178,3$)$ que en los de geometría estable $(50,14 \%$; en votos, 175,5$)$, en los que es muy estrecho el resultado.

\section{5. . Conclusión}

Este artículo pretendía profundizar en el análisis de un tipo específico de gobiernos minoritarios, los de carácter sustantivo, desde una perspectiva espacial, con la pretensión de estudiar, de un modo más preciso, el origen, viabilidad y formación de este tipo de gabinetes, así como las condiciones políticas necesarias para su 
estabilidad y efectividad. Con los instrumentos de la teoría espacial, aplicados a los procesos de formación de gobiernos y a la elaboración legislativa, hemos podido contrastar las hipótesis formuladas en relación con la importancia de la posición central de los partidos que dirigen este tipo de gobiernos de carácter minoritario. Así, de acuerdo a nuestra primera hipótesis (H1), se han mostrado las ventajas que los partidos situados en posiciones centrales tienen para sostener gobiernos minoritarios sustantivos. De acuerdo a la segunda hipótesis formulada (H2), se han expuesto las ventajas de los partidos situados centralmente en el espectro político para poder avanzar en su agenda legislativa.

Asimismo, este estudio tenía como objetivo profundizar en el análisis de los distintos subtipos de gobiernos minoritarios sustantivos, la variante más interesante de los gabinetes minoritarios. El desarrollo de la distinción entre gobiernos minoritarios de "geometría variable" y de "geometría estable" nos ha permitido incorporar, como una categoría analítica útil, el concepto de "geometría variable", tan presente en los debates políticos y en los medios de comunicación. Esta conceptualización permite mostrar las dificultades de los partidos no centrales para estabilizar gobiernos minoritarios sustantivos, tanto desde la perspectiva de la viabilidad de los mismos, al no poder vetar la constitución de otros gabinetes alternativos, como desde el punto de vista de su débil capacidad legislativa. El análisis empírico confirma la mayor eficacia legislativa de los gobiernos minoritarios sustantivos de geometría estable, que es similar al output legislativo de los gobiernos minoritarios formales. Estos datos se confirman tanto para proyectos de ley o proposiciones de ley como para la ley de presupuestos en los casos estudiados.

Los modelos espaciales muestran que los partidos centrales son capaces de constituir y estabilizar gobiernos minoritarios tanto formales como sustantivos y, en este caso, proporcionan más estabilidad y eficacia a los gobiernos sustantivos de "geometría variable". El análisis permite, además, avanzar en los estudios acerca de las condiciones políticas para el desarrollo de gobiernos minoritarios de "geometría variable" y explorar algunos de sus elementos característicos, como el desarrollo de las "estrategias de empaquetado" o los cambios dinámicos en las alianzas y en los partidos de apoyo de este tipo de gabinetes. Más que centrarse en los gobiernos minoritarios como una categoría única, la futura agenda de las investigaciones en este campo debería orientarse a la especificación de subtipos y las condiciones, teóricas y políticas, que los hacen posibles y viables, y su diferente output legislativo.

\section{Bibliografía}

Ajenjo, N. (2015): "Why Minority Governments in Spain? How the Party System Undermines Investiture Rules", en B. E. Rasch, S. Martin y J. A. Cheibub (eds.), Parliaments and Government Formation: Unpacking Investiture Rules, Oxford, Oxford University Press, pp. 153-164.

Austen-Smith, D. y J. Banks (1990): "Stable Portfolio Allocations", American Political Science Review, 84, pp. 891-906. 
Bale, T. y T. Bergman (2006): "Captives No Longer, but Servants still? Contract Parliamentarism and the New Minority Governance in Sweden and New Zealand", Government and Opposition, 41(3), pp. 422-449. https://doi.org/10.1111/j.1477-7053.2006.00186.x

Baron, D. (1991): "A Spatial Bargaining Theory of Government Formation in Parliamentary Systems", American Political Science Review, 85, pp. 137-165.

Bergman, T. (1993): "Formation Rules and Minority Governments", European Journal of Political Research, 23, pp. 55-66. https://doi.org/10.1111/j.1475-6765.1993.tb00348.x

Bergman, T. (1995): Constitutional Rules and Party Goals in Coalition Formation: An Analysis of Winning Minority Governments in Sweden, Umea, Suecia, Umea University.

Calvet Crespo, J. (2003): "Gobiernos minoritarios, pactos parlamentarios y producción legislativa en España”, Política y Sociedad, 40(2), pp. 89-103.

Cheibub, J. A.; S. Martin; y B. E. Rasch (2015): "Government Selection and Executive Powers: Constitutional Design in Parliamentary Democracies", West European Politics, 38(5), pp. 969-996.

https://doi.org/10.1080/01402382.2015.1045289

Christiansen, F.J. y E. Damgaard (2008): "Parliamentary Opposition under Minority Parliamentarism: Scandinavia”, The Journal of Legislative Studies, 14(1/2), pp. 46-76. https://doi.org/10.1080/13572330801920937

Christiansen, F. J. y H. B. Seeberg (2014): "Minority Coalition Governance in Denmark", Party Politics, 20(6), pp. 940-949. https://doi.org/10.1177/1354068812462924

Colomer, J. M. y F. Martínez (1995): “The Paradox of Coalition Trading”, Journal of Theoretical Politics, 7(1), pp. 41-63. https://doi.org/10.1177/0951692895007001003

Falcó-Gimeno, A. e I. Jurado (2011): "Minority Governments and Budget Deficits: The Role of the Opposition”, European Journal of Political Economy, 27, pp. 554-565.

Field, B. N. (2009): "Minority Governments and Legislative Politics in a Multilevel State: Spain under Zapatero", South European Society and Politics, 14(4), pp. 417-434. https://doi.org/10.1080/13608740903503829

Field, B. N. (2014): "Minority Parliamentary Government and Multilevel Politics: Spain's System of Mutual Back Scratching", Comparative Politics, 46(3), pp. 293-312. https://doi.org/10.5129/001041514810943090

Field, B. N. (2016): Why Minority Governments Work. Multilevel Territorial Politics in Spain, Nueva York, Palgrave Macmillan.

https://doi.org/10.1057/9781137559807

Garrido, A. (1995). Parliamentarism vs. Presidentialism: The Spanish Case. Journal of Behavioral and Social Sciences 2, 130-151.

Garrido, A. (2019). "Presidencialismo vs. Parlamentarismo: El caso de España", en J. Reynoso Nuñez, ed., La democracia en su contexto: Segunda edición renovada en homenaje a Dieter Nohlen en su octogésimo aniversario, México, UNAM, 507-554.

Green-Pedersen, C. (2001): "Minority Governments and Party Politics: The Political and Institutional Background to the «Danish Miracle»", Journal of Public Policy, 21(1), pp. 53-70. https://doi.org/10.1017/S0143814X01001039

Hamann, K. y C. Mershon (2008): "Regional Governments in Spain: Exploring Theories of Government Formation", en B. N. Field y K. Hamann, eds., Democracy and 
Institutional Development: Spain in Comparative Theoretical Perspective, Nueva York, Palgrave Macmillan, 110-134.

Heller, W. B. (2002): "Regional Parties and National Politcs in Europe: Spain's Estado de las Autonomías, 1993 to 2000”, Comparative Political Studies, 35(6), pp. 657-685. https://doi.org/10.1177/0010414002035006002

Klüver, H. y R. Zubek (2018). "Minority Governments and Legislative Reliability: Evidence from Denmark and Sweden", Party Politics, 24(6), pp. 719-730. https://doi.org/10.1177/1354068817695742

Laver, M. y K. Shepsle (1996): Making and Breaking Governments: Cabinets and Legislatures in Parliamentary Democacies, Cambridge, Cambridge University Press.

Lijphart, A. (2012): Patterns of Democracy: Government Forms and Performance in Thirty-Six Countries, New Haven, Yale University Press.

Maurer, L. M. (2008): El poder del Parlamento: Congreso y políticas públicas en España, Madrid, Centro de Estudios Políticos y Constitucionales.

Mershon, C. (2002): The Costs of Coalition, Stanford, Stanford University Press.

Miller, N. R., B. Grofman y S. L. Feld (1989): “The Geometry of Majority Rule”, Journal of Theoretical Politics 1(4), pp. 379-406.

Miller, G. J. y T. H. Hammond (1990): "Committees and the Core of the Constitution", Public Choice 66, pp. 201-227.

Montabes, J., A. Garrido y A. Martínez (2019): "El gobierno", en J. Montabes y A. Martínez, eds., Gobierno y política en España, Valencia, Tirant lo Blanch, 189-234.

Nohlen, D. y A. Garrido (2020): Presidencialismo comparado. América Latina, Madrid, CEPC.

Reniu, J. M. (2002): La formación de gobiernos minoritarios en España, 1977-1996, Madrid, Centro de Investigaciones Sociológicas, 2002.

Reniu, J. M. (2011): "Spain is Different: Explaining Minority Governments by Diverging Party Goals", en R. B. Andeweg, L. De Winter y P. Dumont, eds., Puzzles of Government Formation: Coalition Theory and Deviant Cases, Londres, Routledge, 112-128.

Román, P. y J. Ferri (2003): “Gobiernos y estrategias de coalición”, Politica y Sociedad, 40(2), pp. 13-24.

Schofield, N. (1993): "Political Competition and Multiparty Coalition Governments", European Journal of Political Research, 23(1), pp. 1-33. https://doi.org/10.1111/j.1475-6765.1993.tb00346.x

Stefuriuc, I. (2013): Government Formation in Multi-Level Settings: Party Strategy and Institutional Constraints, Nueva York: Palgrave Mcmillan.

Strom, K. (1984): "Minority Governments in Parliamentary Democracies: The Rationality of Non-winning Cabinet Solutions," Comparative Political Studies 17(2), pp. 199-227. https://doi.org/10.1177/0010414084017002004

Strom, K. (1990): Minority Government and Majority Rule, Cambridge, Cambridge University Press.

Tsebelis, G. (1995): "Veto Players and Law Production in Parliamentary Democracies", en H. Döring, ed., Parliaments and Majority Rule in Western Europe, Frankfurt, Campus, pp. 83-111.

Tsebelis, G. (2002): Veto Players. How Political Institutions Work, Princeton, N. J., Princeton University Press. 
Van Roozendaal, P. (1993): “Cabinets in the Netherlands (1918-1990): The Importance of «Dominant» and «Central» Parties", European Journal of Political Research, 23, pp. 35-54.

https://doi.org/10.1111/j.1475-6765.1993.tb00347.x

Vowles, J. (2010): "Making a Difference? Public Perceptions of Coalition, Single-Party and Minority Governments", Electoral Studies, 29(3), pp. 370-380.

https://doi.org/10.1016/j.electstud.2010.03.006 